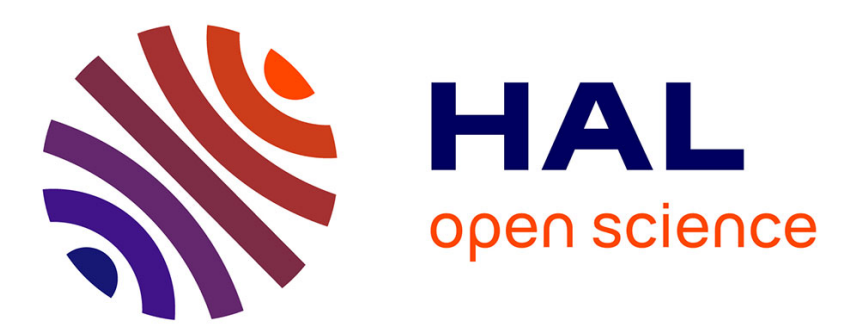

\title{
Comparison of three different scales techniques for the dynamic mechanical characterization of two polymers (PDMS and SU8)
}

\author{
J. Le Rouzic, P. Delobelle, P. Vairac, B. Cretin
}

\section{- To cite this version:}

J. Le Rouzic, P. Delobelle, P. Vairac, B. Cretin. Comparison of three different scales techniques for the dynamic mechanical characterization of two polymers (PDMS and SU8). European Physical Journal: Applied Physics, 2009, 48, pp.11201. 10.1051/epjap/2009124 . hal-00499240

\author{
HAL Id: hal-00499240 \\ https://hal.science/hal-00499240
}

Submitted on 9 Jul 2010

HAL is a multi-disciplinary open access archive for the deposit and dissemination of scientific research documents, whether they are published or not. The documents may come from teaching and research institutions in France or abroad, or from public or private research centers.
L'archive ouverte pluridisciplinaire HAL, est destinée au dépôt et à la diffusion de documents scientifiques de niveau recherche, publiés ou non, émanant des établissements d'enseignement et de recherche français ou étrangers, des laboratoires publics ou privés. 


\title{
Comparison of three different scales techniques for the dynamic mechanical characterization of two polymers (PDMS and SU8) \\ J. Le Rouzic ${ }^{1}$, P. Delobelle ${ }^{2}$, P. Vairac ${ }^{1}$ and B. Cretin ${ }^{1}$
}

\author{
${ }^{1}$ FEMTO-ST, Départ. MN2S, CNRS UMR 6174, Université de Franche-Comté, 32 avenue de \\ l'Observatoire, 25044 Besançon Cedex, France \\ ${ }^{2}$ FEMTO-ST, Départ. Mécanique Appliquée, CNRS UMR 6174, Université de Franche-Comté, \\ 24 chemin de l'Epitaphe, 25000 Besançon, France
}

Corresponding author : patrick.delobelle@univ-fcomte.fr

PACS : 81-70.q: Methods of materials testing and analysis, 81-05.Lg: Polymers and plastics, 83.60.Bc: Linear viscoelasticity.

\begin{abstract}
:
In this article the dynamic mechanical characterization of PDMS and SU8 resin using dynamic mechanical analysis, nanoindentation and the scanning microdeformation microscope have been presented. The methods are hereby explained, extended for viscoelastic behaviours, and their compatibility underlined. The storage and loss moduli of these polymers over a wide range of frequencies (from $0.01 \mathrm{~Hz}$ to some $\mathrm{kHz}$ ) have been measured. These techniques are shown fairly matching and the two different viscoelastic behaviours of these two polymers have been exhibited. Indeed, PDMS shows moduli which still increase at $5 \mathrm{kHz}$ whereas SU8 ones decrease much sooner. From a material point of view, the Havriliak and Negami model to estimate instantaneous, relaxed moduli and time constant of these materials has been identified.
\end{abstract}

\section{1 - Introduction}

In the field of materials sciences it is quite hard to have matching mechanical characterization methods at very small scale. This has become possible only in the last few years especially thanks to scanning probe microscopy $[1,2,3,4,5,6,7]$ and nanoindentation $[8,9,10]$. Viscoelastic properties of polymers have also been measured for low frequencies and for higher frequencies thanks to the time-temperature equivalence [11]. Yet, direct measurements at high frequencies are far less studied in the literature of materials. 
In this paper, three techniques of dynamic mechanical characterization working at different scales have been used. A Dynamic Mechanical Analysis (DMA) is a technique working at macro scale by tensile tests. The Scanning Microdeformation Microscope (SMM) $[12,13]$ is a type of AC-force microscope, a non destructive system which allows quantitative measurements of elastic properties at micro scale. At last, nanoindentation tests which can characterize materials at nano or micro scale and for quasi-static or dynamic loadings have been carried out. We decided to characterize two polymers by measuring their complex Young's moduli for a wide range of frequencies to exhibit their viscoelastic properties. We chose two very different organic materials often used in MEMS applications, PDMS and SU8 resin. PolyDiMethylSiloxane (PDMS) is a silicon-based elastomer. Mechanical properties of this very versatile material vary with preparation conditions. Young's moduli values can actually fluctuate in the range of $0.1 \mathrm{MPa}$ to some tens of MPa depending on its preparation [14, 15, 16, 17]. It exhibits an important viscoelastic behaviour. The other material we decided to characterize is a SU8 resin film. This resin is a polymer based on epoxies which is used for photolithography and MEMS applications and has a Young modulus in the range 3-6 GPa associated with a low viscoelastic behaviour [18].

Bulk samples have been designed to allow DMA measurements and to verify the compatibility of these techniques. To our knowledge such a comparison on viscoelastic materials has not been yet reported in the literature. This is the principal aim of this study performed on these two very different polymers. The material point of view will be briefly analyzed at the end of this paper.

\section{2 - Materials and experimental procedures}

\subsection{Materials}

Polydimethylsiloxane (PDMS) has become the most popular building material used in a variety of low-cost acqueous microfluidic devices aimed in particular at single use for biological or medical diagnostics. In order to have low power consumption, many groups use this material for the manufacture of mobile part (often membrane, bridge,...) in active systems such as microvalves and micropumps. Therefore the characterization of the dynamic mechanical properties of PDMS is of great interest. To realize the PDMS samples, the Sylgard 184 PDMS Kit manufactured by Dow Corning Corporation and composed by a prepolymer and a curing agent has been used. The samples were made by the same method. The prepolymer and curing 
agent in ratio 10:1 were mixed with an Ultra Turax homogenizer for 30s. The solution was poured into a Petri dish up to a thickness of about 3-4 $\mathrm{mm}$ and degassed in a desiccator by application of vacuum for $15 \mathrm{mn}$ with a cycle of $2 \mathrm{mn}$ at $0.5 \mathrm{~m}$ Torr. The solution was then cured in an oven at $65^{\circ} \mathrm{C}$ for $4 \mathrm{~h}$ following the recommendations from Dow Corning. PDMS was demolded and cut to make rectangular specimens. Different samples have been tested. Specimen 1 was tested thanks to the three different techniques for aging times $t_{v}$ of about 1500 hours and $11000 \mathrm{~h}$ at constant temperature $\mathrm{T} \approx 20-22^{\circ} \mathrm{C}$ in a closed Petri dish and without light exposure. Specimen 2 is a very old sample which has been aging for a long time $\left(t_{v}>3\right.$ years) at room temperature $\left(20\right.$ to $\left.30{ }^{\circ} \mathrm{C}\right)$, without any particular precaution and whose preparation conditions are not exactly the same as those previously presented for specimen 1 . Thus, these two PDMS samples must be considered as two different materials.

The SU8 resin is a negative epoxy type photoresit which has been developed by IBM (Watson Research Center). This polymer is a good material for MEMS applications. Two different samples have been tested. Specimen 1, tested with the three techniques, is a film of $0.13 \mathrm{~mm}$ thick obtained by spin-coating liquid SU8 resin (for $30 \mathrm{~s}$ at $5000 \mathrm{rpm} / \mathrm{s}$ ) on a glass substrate. Before the deposition a deshydratation base of $1 \mathrm{~h}$ at $200^{\circ} \mathrm{C}$ has been realized. The final step, after deposition, is a curing of $5 \mathrm{mn}$ at $120{ }^{\circ} \mathrm{C}$. The obtained film was removed from the glass substrate and then cut to make the different samples, one sample for each technique. Specimen 2 is a film of $50 \mu \mathrm{m}$ thick deposited on $\langle 100\rangle$ silicon substrate by spin-coating liquid resin (for $120 \mathrm{~s}$ at $500 \mathrm{rpm} / \mathrm{s})$. A first soft-bake deshydration of $1 \mathrm{~h}$ at $50{ }^{\circ} \mathrm{C}$ followed by a hard-bake of 15 $\mathrm{h}$ at $90{ }^{\circ} \mathrm{C}$ have been performed. Due to the small thickness of these films, only nanoindentation and SMM procedures have been carried out.

\subsection{Dynamic Mechanical Analysis (DMA)}

DMA measures with frequencies in the range of $10^{-2}-100 \mathrm{~Hz}$ were performed on a commercial BOSE Electroforce 3200 machine, at room temperature for the three different materials and at $\mathrm{T}=23,0,-20,-40,-60^{\circ} \mathrm{C}$ for the PDMS sample 1 . Thus, for this specimen the time-temperature equivalence has been analyzed over a large domain of frequency; $10^{-2}<\mathrm{f}<10^{5} \mathrm{~Hz}$.

For PDMS and SU8 resin (specimen 1) samples, gage lengths of the specimens were about 30 $\mathrm{mm}$ and $36 \mathrm{~mm}$ for a cross section of about $13 \times 3-4 \mathrm{~mm}^{2}$ and $10.2 \times 0.13 \mathrm{~mm}^{2}$ respectively. A control on the position with a peak to peak amplitude of $0.5 \mathrm{~mm}$ (corresponding to a strain of \pm 7.6.10 ${ }^{-3}$ ) for a preload strain of $9.1 .10^{-3}$ was realized. Thus the samples were always in tension 
even at the low point of the cycles. According to the ASTM Standard Guide for Dynamic Testing the software calculates the phase angle $\phi$ between the imposed displacement and the measured force and uses the specimen shape to convert the stiffness and the phase information to provide the values of E', the storage modulus, E", the loss modulus and $\tan (\phi)$, the tangent of the phase angle. Moreover, for the specimens 1 (PDMS and SU8), the evolution of E' and E" with the aging time $t_{v}$ has been studied between 3 to about 1300 hours.

\subsection{The Scanning Microdeformation Microscope (SMM)}

\subsubsection{Presentation of the microscope}

The SMM is a type of AC-force contact microscope. The sensor is a micromechanical resonator (Fig. 1) composed of a silicon cantilever with a small sharp sapphire tip at the end. The cantilever is glued onto a piezoelectric bimorph transducer at the other end. The transducer excites the vibration of the tip-sample system. The tip remains in contact with the sample and vibrates at some $\mathrm{kHz}$ with an amplitude of some nanometres. Amplitude and phase of the cantilever vibration are measured with a high sensitivity heterodyne interferometer $[19,20]$. The synoptic of the SMM is presented in Fig. 2.

The signal at the probe output is averaged with the double-phase lock-in amplifier and the amplitude and the phase of the cantilever displacement are recorded by the computer. Moreover, a modulated laser diode is used in a deflectometer to control the static force applied on the sample thanks to the second lock-in (and the third one can be used for a transmission mode operation). This microscope is an effective tool to record images of surfaces and subsurfaces with heterogeneous local elasticity or to characterize elastic properties of a material.

In the framework of this study, it has been used to measure Young's moduli. So we put the tip in contact with the sample and an additional static force is applied by vertically displacing the clamped end of the cantilever is applied. Then the excitation frequency is scanned. The resonant frequency depends on the static force applied via the contact stiffness. Actually, by measuring this resonant frequency, local contact stiffness can be estimated and then, with a well-suited model, the local Young's modulus is extracted. Other ultrasonic non-invasive methods like atomic force acoustic microscope (AFAM), ultrasonic force microscopy (UFM) or AFM spectroscopy with heterodyne interferometer can make such a characterization on the nanometre 
scale but with less accuracy because the contact model must take into account additional forces at this scale $[1,2,3,7]$.

\subsubsection{Model}

A continuous model (Fig. 3) has been used [6, 21] to obtain Young's moduli values of tested samples from the measured contact resonant frequencies. The cantilever is represented as a beam interacting with the sample through two springs $\mathrm{k}_{\mathrm{N}}^{\prime}$ and $\mathrm{k}_{\mathrm{T}}$. The piezoelectric bimorph transducer action on the cantilever has been modelled as a simple mass $\mathrm{m}_{\mathrm{p}}$ and a spring $\mathrm{k}_{\mathrm{p}}$. A Hertz contact has been considered to obtain the expression of the contact stiffness, $\mathrm{k}_{\mathrm{N}}^{\prime}$ :

$$
\mathrm{k}_{\mathrm{N}}^{\prime}=\mathrm{E}^{* 2 / 3}\left(6 \mathrm{RF}_{0}\right)^{1 / 3}
$$

However, for polymers, a dynamic Hertz contact is needed to consider the frequency dependence of the Young's modulus [22, 23], thus :

$$
\mathrm{k}_{\mathrm{N}}^{\prime}=\frac{\mathrm{E}_{1}^{*}}{\mathrm{E}_{0}^{* 1 / 3}}\left(6 \mathrm{RF}_{0}\right)^{1 / 3}
$$

Where $E_{0}^{*}$ is the static reduced Young's modulus of the sample, $E_{1}^{*}$ is the dynamic reduced Young's modulus for the considered frequency, $\mathrm{F}_{0}$ is the static additional force and $\mathrm{R}$ the radius of the tip. This relation is different from the static one (Eq. 1). If $\mathrm{E}_{1}^{*}=\mathrm{E}_{0}^{*}=\mathrm{E}^{*}$, (Eq. 2) is identical to (Eq. 1). For viscoelastic materials it's absolutely necessary to use this new relation because the dynamic Young's modulus can be very different from the static one. It will be the case for PDMS whereas for the SU8 resin we can keep the static relation $\left(E_{1}^{*} \approx E_{0}^{*}\right)$.

To extract the Young's modulus value from the contact resonant frequency $\mathrm{f}_{0}$, the linear differential equation for the vibration of the beam with boundary conditions has been solved [21]:

$$
E_{c} I \frac{\partial^{4} y}{\partial x^{4}}+\rho S \frac{\partial^{2} y}{\partial t^{2}}=0
$$


where $E_{c}$ is the Young's modulus, I the area moment of inertia, $\rho$ the volume density and $S$ the cross section of the cantilever.

In this study a simple spring-mass approximation has been introduced to take into account the damping and to determine the complex Young's modulus like Arinéro et al. [24] did for an AFM. First, the relation between $\mathrm{f}_{0}$ and $\mathrm{k}_{\mathrm{N}}^{\prime}$ is obtained:

$$
\mathrm{f}_{0}=\frac{1}{2 \pi} \sqrt{\frac{\mathrm{k}_{\mathrm{N}}^{\prime}+\mathrm{k}_{\mathrm{c}}}{\mathrm{m}_{\mathrm{eff}}}}
$$

where $\mathrm{k}_{\mathrm{c}}$ is the beam stiffness. The linear differential equation describing the response of an oscillator, with $\mathrm{m}_{\mathrm{eff}}$ the effective mass of cantilever and tip, $\tilde{\mathrm{x}}$ the complex value of the response, $\omega_{0}$ the cantilever-tip-sample system's resonance angular frequency and $\lambda$ the damping coefficient is:

$$
\frac{\partial^{2} \tilde{x}}{\partial t^{2}}+2 \lambda \frac{\partial \tilde{x}}{\partial t}+\omega_{0}^{2} \tilde{x}=\frac{F_{0}}{m_{e f f}} \exp (i \omega t)
$$

with: $\tilde{\mathrm{x}}=\mathrm{X}_{0} \exp (\mathrm{i} \omega \mathrm{t}) \exp (\mathrm{i} \phi)$.

So,

$$
\mathrm{X}_{0} \exp (\mathrm{i} \phi)=\frac{\mathrm{F}_{0} / \mathrm{m}_{\mathrm{eff}}}{\left(\omega_{0}^{2}-\omega^{2}\right)+2 \mathrm{i} \omega \lambda}
$$

Introducing the resonance frequency of the system $f_{0}$ and the $3 \mathrm{~dB}$ half-bandwidth $\mathrm{f}_{1}$, given by $\mathrm{f}_{0}=\omega_{0} / 2 \pi$ and $\mathrm{f}_{1}=\lambda / 2 \pi$, the expression of the complex contact dynamic stiffness can be obtained:

$$
\mathrm{k}_{\mathrm{CCD}}=\frac{\mathrm{F}_{0}}{\mathrm{X}_{0} \exp (\mathrm{i} \phi)}=\mathrm{m}_{\mathrm{eff}}\left(4 \pi^{2}\left(\mathrm{f}_{0}^{2}-\mathrm{f}^{2}\right)+8 \mathrm{i} \pi^{2} \mathrm{ff}_{1}\right)
$$

By taking the imaginary part, and as $\mathrm{f}$ is close to $\mathrm{f}_{0}$, the $\mathrm{k}_{\mathrm{N}}$ stiffness is obtained: 


$$
\mathrm{k}_{\mathrm{N}}^{\prime \prime}=8 \mathrm{~m}_{\mathrm{eff}} \pi^{2} \mathrm{f}_{0} \mathrm{f}_{1}
$$

Introducing the complex effective Young modulus $\mathrm{E}_{\mathrm{X}}^{*}$ :

$$
\mathrm{E}_{\mathrm{x}}^{*}=\mathrm{E}^{*}+\mathrm{i} \mathrm{E}^{* *}
$$

and writing the expression of the complex stiffness as [25]:

$$
\mathrm{k}_{\mathrm{N}}=\mathrm{k}_{\mathrm{N}}^{\prime}+\mathrm{ik}_{\mathrm{N}}^{\prime \prime}
$$

with a static Hertz contact :

$$
\mathrm{k}_{\mathrm{N}}^{\prime \prime}=\mathrm{E}^{" * 2 / 3}\left(6 \mathrm{RF}_{0}\right)^{1 / 3}
$$

and thanks to Eqs. (4), (8) and (11), the expression of $\mathrm{E}^{\text {"* }}$ is given by:

$$
\mathrm{E}^{\prime *}=\frac{\left(2\left(\mathrm{k}_{\mathrm{N}}^{\prime}+\mathrm{k}_{\mathrm{c}}\right) \mathrm{f}_{1}\right)^{3 / 2}}{\mathrm{f}_{0}^{3 / 2}\left(6 \mathrm{RF}_{0}\right)^{1 / 2}}
$$

This relation will be used for the SU8 resin as $\mathrm{E}_{1}^{*} \approx \mathrm{E}_{0}^{*}$.

For a dynamic contact:

$$
\mathrm{k}_{\mathrm{N}}^{\prime \prime}=\frac{\mathrm{E}_{1}^{* *}}{\mathrm{E}_{0}^{* 1 / 3}}\left(6 \mathrm{RF}_{0}\right)^{1 / 3}
$$

Thanks to Eqs. (4), (8) and (13), the following expression of $E_{1}^{\prime *}$ has been obtained:

$$
\mathrm{E}^{\prime *}=\frac{2\left(\mathrm{k}_{\mathrm{N}}^{\prime}+\mathrm{k}_{\mathrm{c}}\right) \mathrm{f}_{1} \mathrm{E}_{0}^{* 1 / 3}}{\mathrm{f}_{0}\left(6 \mathrm{RF}_{0}\right)^{1 / 3}}
$$


This relation will be used for the PDMS elastomer.

At last, it is interesting to note that the relations on the components of the complex Young's modulus determined with the hypothesis of static (st) (Eq. 1) or dynamic (dyn) (Eq. 2) Hertz contact are such that :

$$
\mathrm{E}_{\mathrm{dyn}}^{* *}=\left(\mathrm{E}_{\mathrm{st}}^{* *}\right)^{2 / 3} \mathrm{E}_{0}^{* 1 / 3} \text { and } \mathrm{E}_{\mathrm{dyn}}^{* *}=\left(\mathrm{E}_{\mathrm{st}}^{* *}\right)^{2 / 3} \mathrm{E}_{0}^{* 1 / 3}
$$

It is thus possible to write:

$$
\mathrm{E}_{\mathrm{dyn}}^{(\mathrm{i})^{*}}=\mathrm{E}_{\mathrm{st}}^{(\mathrm{i})^{*}}\left(\alpha+(1-\alpha)\left(\frac{\mathrm{E}_{0}^{*}}{\mathrm{E}_{\mathrm{st}}^{(\mathrm{i})^{*}}}\right)^{1 / 3}\right)
$$

with (i) $=($ ' or " ), $\alpha=1$ for a non viscous material and $\alpha=0$ for a viscoelastic material.

\subsubsection{Experimental conditions}

Two different cantilevers have been used for the characterization of these two materials. Thanks to a previous study on the sensitivity of the SMM [23], we chose 2 different cantilevers which are optmized for PDMS and SU8 resin. Actually, we showed that the cantilever stiffness must be chosen close to the contact stiffness to have the best sensitivity. As cantilever stiffness depends on the inverse of the cube of the length, a length of $7 \mathrm{~mm}$ for PDMS and $4.5 \mathrm{~mm}$ for the SU8 which is harder have been chosen. The width and the thickness of the beam are $400 \mu \mathrm{m}$ and $150 \mu \mathrm{m}$ respectively. The tip has a cylindrical base and a conical end as shown in Fig. 1. The sharp end of the tip is spherical. For the beam with a length of $7 \mathrm{~mm}$, the tip length 1 is 697 $\mu \mathrm{m}$, its mass $\mathrm{m}=0.23 \mu \mathrm{g}$ and its curvature radius $\mathrm{R}=45 \mu \mathrm{m}$. For the one with a length of 4.5 $\mathrm{mm}, 1=976 \mu \mathrm{m}, \mathrm{m}=0.45 \mu \mathrm{g}$ and $\mathrm{R}=20 \mu \mathrm{m}$. The static applied force $\mathrm{F}_{0}$ was $0.15 \mathrm{mN}$ for the PDMS and $0.5 \mathrm{mN}$ for the SU8 resin. The frequency domain of the SMM with these cantilevers corresponds to some $\mathrm{kHz}$. As an example, Fig. 4 gives the first resonance mode of the two PDMS samples (specimens 1 and 2). On each sample about 5 to 7 measurements have been performed and the final result is the mean of the values. The shift frequency difference between these two specimens, due to their different modulus, is about $350 \mathrm{~Hz}$. Note that the SMM has 
already been tested on standard hard materials like silicon and silica $[6,21,26]$ and a precision of nearly $5 \%$ have been determined with the used model.

With these experimental conditions the polymers are loaded in their linear viscoelastic regime. Actually, PDMS remains linear until deformations of $60 \%$ [17] and $5 \%$ for SU8 resin [18]. For a spherical tip like SMM ones, deformation of the contact area is $\varepsilon=0.2 \mathrm{a} / \mathrm{R}$ [27], where a is the contact area radius and $\mathrm{R}$ the tip radius. With the tips we have used, $\mathrm{a}<5 \mu \mathrm{m}$ and $\mathrm{R}>20 \mu \mathrm{m}$, thus $\varepsilon<5 \%$.

\subsection{Nanoindentation tests}

\subsubsection{Model}

The Berkovich's indentations were performed with a Nanoindenter II $^{\mathrm{S}}$ (NanoInstruments). The hardness $\mathrm{H}_{\mathrm{b}}$ and the Young's modulus $\mathrm{E}^{*}$ are deduced using the classical static procedure or the continuous stiffness method (CSM) described as follows. One of the most commonly used methods for analysing nanoindentation data is the Oliver and Pharr one [8], which expands on earlier ideas developed by Loubet et al. [28] and Doerner and Nix [29]. This analysis has often been applied to polymer characterization, for example [18], [30] and [31], even if the true contact area is underestimated due to the pushing up of the material around the indenter. In this case the Young's modulus is slightly overestimated. However, in our method described below the Young's modulus has been estimated for an indentation depth close to zero (Eq. (32)) and thus the pile up effect may be considered as negligible.

In the Oliver and Pharr method, the hardness $\mathrm{H}_{\mathrm{b}}$ and the reduced modulus $\mathrm{E}^{*}$ are derived from :

$$
\mathrm{H}_{\mathrm{b}}=\frac{\mathrm{F}_{\max }}{\mathrm{A}}
$$

and

$$
\left(\frac{d F}{d h}\right)_{\text {unloading }}=S_{s}=\frac{2 \eta}{\sqrt{\pi}} E^{*} \sqrt{A} \text { with } \frac{1}{E^{*}}=\frac{1-v_{s}^{2}}{E_{s}}+\frac{1-v_{i}^{2}}{E_{i}}
$$

In these equations, $F_{\max }$ is the maximum indentation load, A the projected area of the elastic contact, $S_{\mathrm{s}}$ the unloading stiffness measured at different maximum depths of penetration $\mathrm{h}$ for the classical method (quasi-static method), or continuously with the CSM technique (at a 
frequency $f=45 \mathrm{~Hz}) . \eta=1.034$ for a Berkovich's tip. $E_{s}$ and $v_{s}$ are the Young's modulus and the Poisson's ratio of the specimen and $E_{i}, v_{i}$ the same parameters for the indenter. The expression of the projected contact area A for a Berkovich indenter is given by the following formula:

$$
\mathrm{A}\left(\mathrm{h}_{\mathrm{c}}\right)=24.56 \mathrm{~h}_{\mathrm{c}}^{2}+\sum_{\mathrm{n}=1}^{4}\left(\mathrm{a}_{\mathrm{n}} \mathrm{h}_{\mathrm{c}}^{1 / \mathrm{n}}\right)
$$

The second term in Eq. (19), evaluated using fused silica as a reference material, takes into account the geometrical deviations due to the tip rounding. Presently, this term is negligible due to the large penetration depths. The displacement $h_{c}$ is given by:

$$
\mathrm{h}_{\mathrm{c}}=\mathrm{h}-\varepsilon \frac{\mathrm{F}_{\max }}{\mathrm{S}_{\mathrm{s}}}
$$

in the case of the classical method. $S_{\mathrm{s}}$ is calculated by analytical differentiating of the experimental unloading curve:

$$
\mathrm{F}=\mathrm{D}\left(\mathrm{h}-\mathrm{h}_{\mathrm{f}}\right)^{\mathrm{m}}
$$

and evaluating the derivative at the peak load $\mathrm{F}_{\max } . \mathrm{h}_{\mathrm{f}}$ is the remanent penetration depth and $\mathrm{m} \approx$ 2 for a Berkovich indenter. For the CSM method, the displacement $h_{c}$ is given by:

$$
\mathrm{h}_{\mathrm{c}}=\mathrm{h}-\varepsilon \frac{\mathrm{F}}{\mathrm{S}_{\mathrm{S}}}
$$

where $S_{\mathrm{s}}$ and $\mathrm{F}$ are the unloading stiffness and the force recorded along the displacement of the indenter, respectively. So, with this method, hardness and Young's modulus can be determined as a function of the penetration depth $\mathrm{h}$. In (20) and (22), $\varepsilon=0.72$ which corresponds to a conical indenter. In the CSM method a small harmonic load oscillation is superimposed to the static one and if the tested material presents a viscoelastic character it is then possible to deduce its complex modulus [32]. If the dynamic loading is given by:

$$
\mathrm{F}=\mathrm{F}_{0} \exp (\mathrm{i} \omega \mathrm{t})
$$


the deformation response of the material is :

$$
\Delta \mathrm{h}=\Delta \mathrm{h}_{0} \exp (\mathrm{i} \omega \mathrm{t}) \exp (\mathrm{i} \phi)
$$

where $\phi$ is the phase lag due to viscous dissipation, as in Eqs. (5) and (6) for the SMM technique. The components of the complex modulus $\mathrm{E}^{*}$ can be calculated according to:

$$
\begin{aligned}
& E^{* *}=S_{d} \frac{\sqrt{\pi}}{2 \eta \sqrt{A}} \cos (\phi) \\
& E^{\prime *}=S_{d} \frac{\sqrt{\pi}}{2 \eta \sqrt{A}} \sin (\phi)
\end{aligned}
$$

with $\mathrm{S}_{\mathrm{d}}=\mathrm{F}_{0} / \Delta \mathrm{h}_{0}$ and thus $\tan (\phi)=\mathrm{E}^{\prime *} / \mathrm{E}^{\prime *}$.

In the present case, for polymer application, $E_{i}>E_{s}\left(\right.$ Eq. 18) and then, $E^{*}=E_{S} /\left(1-v_{S}^{2}\right)$ as in SMM experiments. Now, if $S_{i}, S_{f}$ and $S_{s}$ are the stiffness of the indentation cell, of the load frame and of the sample respectively, the total stiffness $S_{0}$ is :

$$
S_{0}=\left(\frac{1}{S_{s}}+\frac{1}{S_{f}}\right)^{-1}+S_{i}
$$

In our case $S_{f}>S_{s}$, then:

$$
\mathrm{S}_{0}=\mathrm{S}_{\mathrm{S}}+\mathrm{S}_{\mathrm{i}}
$$

Combining Eqs. (18) and (19), we obtain :

$$
E_{s}=\frac{S_{s}}{2 \mu h_{c}} \text { with } \mu=\sqrt{\frac{24.56}{\pi}} \frac{\eta}{1-v_{s}^{2}} \text { and } S_{s}=\frac{d F}{d h}
$$

This relation supposes that the surface of the sample is precisely detected without initial penetration $\left(S_{\mathrm{s}} \gg S_{\mathrm{i}} \approx 44 \mathrm{~N} / \mathrm{m}\right)$. This is the case for metallic materials and hard polymers such 
as the SU8 resin. However, with PDMS, $S_{\mathrm{s}}<\mathrm{S}_{\mathrm{i}}$ and thus when the contact is detected the indenter has penetrated into the sample. In this study we determined the contact with the sample for different fixed stiffnesses $S_{0}$, such that $S_{0}>S_{i}>S_{s}$, that is to say for a certain penetration depth $h_{0}$ function of $S_{0}$. In this case, the measured Young's modulus $E_{m e s}$ is given by:

$$
\mathrm{E}_{\mathrm{mes}}=\frac{\mathrm{S}_{\mathrm{s}}}{2 \mu \mathrm{h}_{\mathrm{mes}}}
$$

where $\mathrm{h}_{\text {mes }}$ is the measured indentation depth penetration.

Due to the quasi-elastic indentation response of the PDMS samples, $\mathrm{h}_{\mathrm{f}} \approx 0$ and $\mathrm{m}=2$ in Eq. (21), and thanks to the relations (19) and (20), it's easily shown that:

$$
\mathrm{h}_{\mathrm{c}}=\alpha_{\mathrm{i}} \mathrm{h} \text { with } \alpha_{\mathrm{i}}<1
$$

Note that the coefficient $\alpha_{i}$ is not the same in quasi-static or dynamic methods. As the measured indentation depth for a given contact stiffness $S_{0}$ is $h_{m e s}=h-h_{0}$, combining Eqs. (29), (30) and (31) the relation (32) is obtained:

$$
\mathrm{E}_{\mathrm{mes}}=\mathrm{E}_{\mathrm{s}}+\mathrm{E}_{\mathrm{s}} \frac{\mathrm{h}_{0}\left(\mathrm{~S}_{0}\right)}{\mathrm{h}_{\mathrm{mes}}}
$$

Thus the representation $E_{\text {mes }}=f\left(1 / h_{\text {mes }}\right) s_{0}$ must be linear ; the intersection with the $Y$ axis gives the value of the true Young's modulus $\mathrm{E}_{\mathrm{s}}$ and the slope of the straight line allows to determine $\mathrm{E}_{\mathrm{s}} \mathrm{h}_{0}\left(\mathrm{~S}_{0}\right)$ which is an increasing function of the initial stiffness $\mathrm{S}_{0}$.

In fact, when $h_{\text {mes }}>h_{0}, E_{\text {mes }}=E_{s}$. Thanks to these representations the $E_{s}$ values for quasi-static condition or for dynamic loading $(\mathrm{f}=45 \mathrm{~Hz})$ can be determined.

In the CSM technique the loss tangent is defined as:

$$
\tan (\phi)=\frac{E^{\prime \prime}}{E^{\prime}}=\frac{\lambda_{0} \omega}{S_{0}-m \omega^{2}}
$$

where $S_{0}$ is given by the relation (28) at the considered frequency, $\lambda_{0}$ is the sum of the damping coefficient of the apparatus and the one of the contact, $m$ is the mass of the moving part of the 
indenter. The measured $\tan (\phi)$ is false as $\lambda_{0}$ and $S_{0}$ are functions of the initial indentation depth $h_{0}$. The true value of the loss tangent corresponds to those at $h=h_{0}+h_{\text {mes }}=0$. Plotting the measured values of $\tan (\phi)$ as a function of $\left(h_{0}+h_{\text {mes }}\right)$, the intersection with the $Y$ axis should give the true value of this parameter. The initial depth penetration $\mathrm{h}_{0}$ can be calculated from the experimental representation of Eq. (32); the slope gives the product $\mathrm{h}_{0} \mathrm{E}_{\mathrm{s}}$ and knowing $\mathrm{E}_{\mathrm{s}}$ previously determined, we calculate the $\mathrm{h}_{0}$ value. This way will be used to determine the $\tan (\phi)$ value of the PDMS samples and thus the loss modulus E" (Eq. (33)). For the SU8 resin, the contact is precisely detected, thus $\mathrm{h}_{0}=0$ and the $\tan (\phi)$ value given by the standard procedure is considered as accurate.

\subsubsection{Experimental conditions}

Nanoindentation tests were performed using a Nanoindenter $\mathrm{II}^{\mathrm{S}}$. As previously mentioned the study was conducted following the classical (quasi-static) and CSM (dynamic at $\mathrm{f}=45 \mathrm{~Hz}$ ) procedures. For each tested sample and for each initial stiffness $S_{0}$, the measurement sequence consists on 5 indents with a $50 \mu \mathrm{m}$ space between them with a maximum penetration depth of $\mathrm{h}_{\max } \cong 4 \mu \mathrm{m}$. The penetration speed was not constant but increased with depth from 2 to 45 nm.s ${ }^{-1}$ with 8 steps such that $\dot{\varepsilon}=(1 / \mathrm{h})(\mathrm{dh} / \mathrm{dt})$ is approximately constant and equal to $2.10^{-2} \mathrm{~s}^{-1}$. The stiffness of the indentation cell $\mathrm{S}_{\mathrm{i}}$ is $44 \mathrm{~N} / \mathrm{m}$ and the values of the imposed initial stiffness are in the range $53<\mathrm{S}_{0}<94 \mathrm{~N} / \mathrm{m}$. For the quasi-static method, four unloadings (to $90 \%$ of the total loading) were performed at about $\mathrm{h}_{\max } \approx 1,2,3$ and $4 \mu \mathrm{m}$ and $50 \%$ of the unloading curves are considered to calculate the contact stiffness of the samples $\mathrm{S}_{\mathrm{S}}$ as previously presented. For the CSM procedure, the indenter vibrates at a frequency of $45 \mathrm{~Hz}$ for an amplitude of 1-2 nm during the indenter penetration $\left(\dot{\varepsilon} \approx 2 \cdot 10^{-2} \mathrm{~s}^{-1}\right)$.

As an example, Fig. 5 shows, for the PDMS sample 1, the evolution of the measured Young's modulus $\mathrm{E}_{\text {mes }}$ obtained with the two methods as a function of the measured indentation depth $\mathrm{h}_{\text {mes }}$ and for different values of $\mathrm{S}_{0}$. As expected by Eq. (32), $\mathrm{E}_{\text {mes }}$ decreases with $\mathrm{h}_{\text {mes }}$. According to Eq. (32), Fig. 6 gives the representations of $E_{\text {mes }}$ as a function of $1 / h_{\text {mes }}$, for the same conditions as those presented in Fig. 5. These representations are linear and lead to determine $\mathrm{E}_{\mathrm{st}}$ $=1.7 \mathrm{MPa}, \mathrm{E}_{\mathrm{dyn}}=2.6 \mathrm{MPa}$ for the classical and CSM methods respectively. Note that, for the same value of $S_{0}$, the slopes of these representations are different, depending on the performed method. Indeed, this is due to the different value of $\alpha_{i}$ in Eq. (31) for quasi-static or dynamic loadings. Thanks to Eq. (32) and knowing $\mathrm{E}_{\mathrm{s}}$ we can evaluate the indentation depth $\mathrm{h}_{0}$ 
corresponding to the initial stiffness $S_{0}$. For instance, in the case of the sample 1 , if $\left(\mathrm{S}_{0}-\mathrm{S}_{\mathrm{i}}\right) \approx 25$ $\mathrm{N} / \mathrm{m}, \mathrm{h}_{0} \approx 4 \mu \mathrm{m}$.

In the case of the SU8 films the maximum penetration depth has been fixed at $\mathrm{h}_{\max }=3 \mu \mathrm{m}$ and the contact between the surface of the sample and the indenter tip is easily detectable. Thus, the measured values of the Young's modulus and of the hardness are constant overall the indentation depth.

\section{3 - Experimental results}

The three techniques work at different scales and at different frequencies. As previously shown, they enable us to check the viscoelastic properties of these polymers. Actually, storage and loss moduli of polymers change depending on the frequency. We recorded the measures of $\mathrm{E}^{\prime}$ and $\mathrm{E}^{\prime \prime}$ for the two specimens of PDMS and for the two SU8 resin films.

\subsection{Case of the PDMS samples}

We took $v=0.48$ for the Poisson's ratio of the PDMS (hyperelastic material). The values of $E^{\prime}$ for the two PDMS samples are plotted in Fig. 7 as a function of the working frequency and for the three experimental techniques. Note that for the SMM value, $\mathrm{f}$ is the first contact resonance frequency equal to $4,18 \mathrm{KHz}$. The measures given by the DMA and the nanoindentation methods are in a fairly good agreement. The SMM ones even if it is two decades further show a possible continuity. Static moduli $\mathrm{E}_{0}^{*}$ for the two samples are respectively 1.7 and $2.9 \mathrm{MPa}$. As it will be shown, this difference is principally due to the different preparation conditions and weakly to the aging time. Storage modulus increases with the frequency for the two samples, which is typical of a viscoelastic material. For these two materials the values given by the SMM at nearly $4 \mathrm{kHz}$ are 3.4 and $5.5 \mathrm{MPa}$ (Fig. 7). In the Fig. 8 the loss modulus is plotted as the function of the working frequency. At $0.01 \mathrm{~Hz}$ the values are very low, near zero, but sharply increase with the working frequency. Results between DMA and SMM show the same behaviour for E" than for E'. Typically, for polymers, E" increases before reaching a maximum and then decreases with the working frequency. The SMM values of $\mathrm{E}^{\prime \prime}$ at $4 \mathrm{kHz}$ for the two specimens are about 1 and $1.6 \mathrm{MPa}$.

$E^{\prime}$ and $E^{\prime \prime}$ are of the same order of magnitude which means that for this range of frequencies the material is very viscoelastic. This behaviour is quantified by the parameter $\tan (\phi)=\mathrm{E}^{\prime \prime} / \mathrm{E}^{\prime}$ as 
shown in Fig. 9. The values estimated with the CSM nanoindentation procedure are in good agreement with those obtained by the DMA analysis. The SMM values also show a possible continuity. The $\tan (\phi)$ parameter is an increasing function of the frequency, as expected, and the SMM values are close to 0.28 for $\mathrm{f} \approx 4 \mathrm{kHz}$. It should then decrease for higher frequencies, the maximum value should be obtained at a frequency of about $10^{6} \mathrm{~Hz}$. From a material point of view, it is interesting to note that the values of the $\tan (\phi)$ parameter are the same for the two tested specimens, indicating that this parameter seems insensitive to the elaboration conditions and the aging time as it will be shown later.

To compare in a more quantitative manner the results obtained by the DMA and the SMM techniques, DMA experiments at low temperatures $\left(T=0,-20,-40,-60^{\circ} \mathrm{C}\right)$ on specimen 1 have been carried out. The frequency range is 0.01 to $50 \mathrm{~Hz}$ and thus, thanks to the time-temperature equivalence, a large domain of frequency can be analyzed; $10^{-2}<\mathrm{f}(\mathrm{Hz})<10^{7}$. However, for the specimen 1, between the first experiments previously presented (Figs. 7, 8, 9) for a relatively short aging time $\left(t_{v}=1460 \mathrm{~h}\right)$ and these new measures $\left(t_{v}=11000 \mathrm{~h}\right.$, Figs. 11-12-13), the material has evolved over a very long time at room temperature. The effect of aging time has been analyzed thanks to the DMA technique and figure 10 shows the increasing of the normalized storage modulus $E\left(t_{v}\right) / E^{\prime}(4 h)\left(E^{\prime} /\left(t_{v}\right)\right.$ measured at an aging time $t_{v}$ over the modulus measured just after the elaboration of the material, $\left.E^{\prime}(4 h)\right)$ as a function of the aging time $t_{v}$ and for three frequencies. So, between these two experiments, the storage modulus (and also the loss modulus) has grown of about $14 \%$. The William-Landel and Ferry model has been applied to calculate the storage and loss moduli master curves as shown in Figs. 11 and 12 respectively. In this model, for a fixed reference temperature $T_{0}$, the translation parameter $a_{T / T_{O}}$ of the frequencies, is given by:

$$
\mathrm{E}^{(\mathrm{i})}(\mathrm{T}, \mathrm{f})=\mathrm{E}^{(\mathrm{i})}\left(\mathrm{T}_{\mathrm{o}}, \mathrm{a}_{\mathrm{T} / \mathrm{T}_{\mathrm{O}}}^{(\mathrm{i})} \mathrm{f}\right) \text { with } \operatorname{Ln}\left(\mathrm{a}_{\mathrm{T} / \mathrm{T}_{\mathrm{O}}}^{(\mathrm{i})}\right)=\frac{-\mathrm{C}_{1}^{(\mathrm{i})}\left(\mathrm{T}-\mathrm{T}_{0}\right)}{\mathrm{C}_{2}^{(\mathrm{i})}+\mathrm{T}-\mathrm{T}_{0}} \text { and (i)=(' or ") }
$$

In the representations drawn in Figs. 11 and 12, the reference temperature is $\mathrm{T}_{0}=23^{\circ} \mathrm{C}$ and the values of the parameters $\mathrm{C}_{1}^{(\mathrm{i})}$ and $\mathrm{C}_{2}^{(\mathrm{i})}\left({ }^{\circ} \mathrm{C}\right)$ are equally reported in these figures. $\mathrm{E}^{\prime}$ and $\mathrm{E}^{\prime \prime}$ continuously increase with the equivalent frequency $\left(10^{-2}<\mathrm{f}<10^{5} \mathrm{~Hz}\right)$ from 2 to $7.5 \mathrm{MPa}$ and 0.02 to $1.6 \mathrm{MPa}$ respectively. Figure 13 gives the evolution of the parameter $\tan (\phi)=\mathrm{E}^{\prime \prime} / \mathrm{E}^{\prime}$ as a function of the equivalent frequency. 
New nanoindentation and SMM tests have been performed on this aged specimen $\left(t_{v}=11000\right.$ h) and the results are plotted in Fig. 11, 12, 13. As for the previous results (Figs. 7, 8, 9), nanoindentation measures (quasi-static and dynamic) perfectly match those given by the DMA. For the SMM experiments, a new cantilever whose characteristics are: length $6,5 \mathrm{~mm}$, width $400 \mu \mathrm{m}$, thickness $80 \mu \mathrm{m}, 1=697 \mu \mathrm{m}, \mathrm{m}=0.44 \mu \mathrm{g}$ and $\mathrm{R}=45 \mu \mathrm{m}$, has been used. The first resonance mode with an applied static force of $0.15 \mathrm{mN}$ is $\mathrm{f}_{\mathrm{o}}=2,65 \mathrm{KHz}$, which corresponds to $\mathrm{E}^{\prime}=4.39 \mathrm{MPa}\left(\mathrm{E}_{\mathrm{O}}^{*}=2 \mathrm{MPa}\right.$ in Eqs. (2) or (15)). The value of the lost modulus determined from the half-bandwidth $\mathrm{f}_{1}$ of the resonance peak is $\mathrm{E}^{\prime \prime}=1,19 \mathrm{MPa}$, thus $\tan (\phi)=0.27$. These different values are plotted in Figures 11, 12, 13 and are in a fairly good agreement with the time-temperature equivalent curves. Taking into account the aging of the specimen, resulting in an increasing of $14 \%$ on the values of the Young's modulus components when $t_{v}$ increases from $1460 \mathrm{~h}$ to $11000 \mathrm{~h}$ (Fig. 10), the values of the previous measurements ( $\mathrm{f}_{0}=4,16 \mathrm{KHz}$ ) have also been reported in these figures. They are in the neighbourhood of the master curves.

From a material point of view, it is interesting to note that the values of the $\tan (\phi)$ parameter obtained with these three different techniques on the two specimens are identical, thus insensitive to the aging time and the elaboration conditions. The values measured with the SMM technique $(\tan (\phi) \cong 0.27)$ are slightly higher than those evaluated with the DMA timetemperature equivalence, $\tan (\phi) \cong 0.21$, for the same frequency domain. Indeed, the E" values are slightly overestimated with the SMM method. This observation tends to show that, if $\mathrm{g}\left(\mathrm{t}_{\mathrm{v}}\right.$, ElC) is a function of the aging time $t_{v}$ and the elaboration conditions ElC, the complex modulus should be given by :

$$
\mathrm{E}^{*}=\mathrm{g}\left(\mathrm{t}_{\mathrm{v}}, \mathrm{ElC}\right)\left(\mathrm{E}^{\prime *}+\mathrm{iE} \mathrm{E}^{* *}\right)
$$

As a conclusion, our measures given by the three different techniques working at different scales lead to characterize the PDMS material over a wide range of frequencies $\left(10^{-2}-10^{4} \mathrm{~Hz}\right)$, but with a certain discrepancy due to the difference in the working frequency of these three methods. However, the measures show the compatibility and the complementary of these characterization systems. We quantitatively saw the evolution of storage and loss moduli of these bulk PDMS samples. Indeed, the measured values are in a fairly good agreement with the results reported by Mata et al. [15], Roure et al. [16] and Schneider et al. [17], ie : E' = 1.9 MPa without climate test and for quasi-static measurements. 


\subsection{Case of the SU8 resin}

The same measures on the SU8 resin film have been carried out. For this material we took a Poisson's ratio of $v=0.29$. For the two specimens the evolution of the storage modulus E' with the frequency has been plotted in Fig. 14. This time, the three techniques do not perfectly match. Actually for sample 1, at $0.01 \mathrm{~Hz}$ the DMA value is about $2.9 \mathrm{GPa}$ (2 different measures) whereas the nanoindentation value is about $4.5 \mathrm{GPa}$. Moreover, for these two techniques the storage modulus slightly increases with the frequency in the studied range. The SMM value at $23 \mathrm{kHz}$ (first resonance frequency) confirms the indentation modulus values with a nearly equal value of $4.2 \mathrm{GPa}$. As previously mentioned, the value of the order of $4.5 \mathrm{GPa}$ is in agreement with the results given in the overall literature $\mathrm{E}^{\prime} \approx 4$ to $6 \mathrm{GPa}$. The low values obtained by DMA technique are certainly due to the too small thickness of the tested specimen $(0.13 \mathrm{~mm})$ and the small preload strain $\left(\approx 9.10^{-3}\right)$ allowing to a certain inhomogeneity in the strain field across the specimen section. The artefacts due to the instrument compliance effects observed on rigid specimens are also not neglectible. So in the typical curve of the storage modulus of a polymer, the maximum of slope has already been passed and the modulus is quite constant. The same evolution can be expected for the loss modulus in this range of frequencies. In Fig. 15 a loss modulus which decreases with the frequency can be observed. The nanoindentation value is a slightly greater than the DMA one. The SMM value at $23 \mathrm{kHz}$ is lower and confirms the global decreasing of the loss modulus. It can be noted that the loss modulus if far lower than the storage one (20-80 MPa versus 4-4.5 GPa). Thus, the SU8 resin presents a very weak viscoelastic behaviour, far less than the PDMS one.

The $\tan (\phi)$ has also been plotted in Fig. 16. The maximum has been passed ( $\left.\cong \cong 10^{-2} \mathrm{~Hz}\right)$ and this parameter decreases with the frequency. Of course, the values are much lower than for the PDMS and the maximum value is close to 0.025. It is important to observe that the three techniques perfectly match. DMA and nanoindentation values are the same at $45 \mathrm{~Hz}$ and the SMM value prolongs the decrease of the curve. In fact with DMA technique, the error due to the small thickness of the film (or other causes) has the same effect on the determination of $E^{\prime}$ and $\mathrm{E} "$ and disappears on the loss tangent which is equal to the ratio $\mathrm{E}^{\prime \prime} / \mathrm{E}$.

Nanoindention and SMM measurements have been performed on the same sample (specimen 1) but for an aging time at room temperature of about $13000 \mathrm{~h}$. Contrary to the PDMS samples, no noticeable evolution outside of the method accuracies has been pointed out.

For the SU8 film deposited on the Si substrate (specimen 2), the nanoindentation and the SMM techniques perfectly match (Fig.14) and the determined values of the storage modulus are $5.57 \pm$ 
$0.15 \mathrm{GPa}$ and $5.6 \pm 0.3 \mathrm{GPa}$, respectively. These values are higher than those measured on specimen 1, but close to those reported by Al-Halhouli et al. [18], i.e.: 5.2 GPa. The values of the loss modulus and the tangent of the phase lag are plotted in Figs. 15 and 16. As for the specimen 1 these two parameters decrease with the frequency, but the values are slightly lower than those determined on the previous sample, i.e.: $\mathrm{E}^{\prime}=40 \mathrm{MPa}$ (at $45 \mathrm{~Hz}$ ) and $\mathrm{E} "=8.4 \mathrm{MPa}$ (at $13 \mathrm{KHz}$ ) for the nanoindentation and the SMM procedures, respectively. These observations, increasing of E' and decreasing of E' compared to the values obtained on sample 1, are certainly due to the long bake during $15 \mathrm{~h}$ at $90{ }^{\circ} \mathrm{C}$ performed on this specimen.

Note that the Berkovich hardnesses $\mathrm{H}_{\mathrm{b}}$ of these different polymers are about, $\mathrm{H}_{\mathrm{b}}=0.33 \pm 0.05$ $\mathrm{MPa}$ and $0.55 \pm \mathrm{MPa}$ for the two PDMS samples (specimens 1 and 2 respectively) and $\mathrm{H}_{\mathrm{b}}=330$ $\pm 20 \mathrm{MPa}$ and $\mathrm{H}_{\mathrm{b}}=362 \pm 13 \mathrm{MPa}$ for the two SU8 films (specimens 1 and 2). This last value is in fairly good agreement with the one given by Al-Halhouli et al. [18] $\left(\mathrm{H}_{\mathrm{b}} \approx 430 \mathrm{MPa}\right)$.

\section{4 - Phenomenological modeling}

From a material point of view and for viscoelastic materials as polymers, the crucial problem in vibration experiments concerns the accurate determination of the viscoelastic parameters over a broad range of frequency. So, in the case of sinusoidal deformation, the complex modulus can be written as [34] :

$$
E^{*}=E^{i}+\left(E^{r}-E^{i}\right) \sum_{j=1}^{n} p_{j} \frac{1}{1+i \omega \tau_{j}} \text { with } \sum_{j=1}^{n} p_{j}=1
$$

where $E^{i}$ and $E^{r}$ are the instantaneous and relaxed Young's moduli, respectively. The parameters $\tau_{\mathrm{j}}$ are the different relaxation times and $\mathrm{p}_{\mathrm{j}}$ is a ponderation coefficient for each relaxation time. It is very difficult to determine the values of the parameters $p_{j}, \tau_{j}$ and their number $n$. From a phenomenological point of view, to overcome this difficulty the empirical model of Havriliak and Negami [35] (H-N model) is considered, which combines the advantages of the modelling of Cole et al. [36] and Davidson et al. [37]. In this model, the complex modulus is given by:

$$
E^{*}=E^{i}+\left(E^{r}-E^{i}\right) \frac{1}{\left(1+(i \omega \tau)^{\alpha}\right)^{\beta}}
$$


Thus, storage and loss moduli are respectively given by:

$$
\begin{gathered}
E^{\prime}=E^{i}+\left(E^{r}-E^{i}\right) \frac{\cos (\beta \phi)}{\left(1+2(\omega \tau)^{\alpha} \cos (\alpha \pi / 2)+(\omega \tau)^{2 \alpha}\right)^{\beta / 2}} \\
E^{\prime \prime}=\left(E^{i}-E^{r}\right) \frac{\sin (\beta \phi)}{\left(1+2(\omega \tau)^{\alpha} \cos (\alpha \pi / 2)+(\omega \tau)^{2 \alpha}\right)^{\beta / 2}} \\
\text { with } \phi=\tan ^{-1}\left(\frac{(\omega \tau)^{\alpha} \sin (\alpha \pi / 2)}{1+(\omega \tau)^{\alpha} \cos (\alpha \pi / 2)}\right)
\end{gathered}
$$

where $\tau$ is a single parameter with time dimension and $\alpha, \beta$ two empirical parameters.

Note that if $\alpha=\beta=1$, the equation (37) with a single relaxation time is obtained. The different experimental curves of Figs. 11, 12 and 13 for the PDMS and Figs. 14, 15 and 16 for the SU8 resin have been fitted by equations (38), (39), (40) and the results drawn on these figures. The identified values of the parameters are listed in Table 1. Note that these values correspond to the working range of frequencies and cannot be used for very higher frequencies.

The simulations are fairly good especially considering on the one hand the three different experimental techniques that have been used and on the other hand the wide range of frequency which has been analysed. Notice the very great difference between the time parameter of the PDMS and the SU8 resin's one; the PDMS is very viscous $\left(\tan (\phi) \approx 0.21\right.$ at $\left.\mathrm{f}=10^{4} \mathrm{~Hz}\right)$ contrary to the SU8 resin $\left(\tan (\phi) \approx 0.005\right.$ at $\mathrm{f}=10^{4} \mathrm{~Hz}$ for sample 1$)$. The same trend is observed on the ratio between the instantaneous and the relaxed moduli, $\mathrm{E}^{\mathrm{i}} / \mathrm{E}^{\mathrm{r}}: \mathrm{E}^{\mathrm{i}} / \mathrm{E}^{\mathrm{r}} \approx 17$ for the PDMS and only $\approx 1.12-1.25$ for the SU8 resin. Note that from an experimental point of view, the timetemperature equivalence experiments performed on PDMS samples with $E^{r}=2 \mathrm{MPa}$ give $\mathrm{E}(\mathrm{f}) / \mathrm{E}^{\mathrm{r}} \cong 7.5$ at $\mathrm{f}=10^{7} \mathrm{~Hz}$ (this study) and from [38] with $\mathrm{E}^{\mathrm{r}} \approx 50 \mathrm{MPa}$ give $\mathrm{E}(\mathrm{f}) / \mathrm{E}^{\mathrm{r}} \approx 10$ at $\mathrm{f}=$ $10^{11} \mathrm{~Hz}$. These results corroborate the value $\mathrm{E}^{\mathrm{i}} / \mathrm{E}^{\mathrm{r}} \approx 17$ presently determined for $\mathrm{f} \rightarrow \infty$.

\section{5 - Conclusion}


In this article the efficiency of the three mechanical characterization methods has been pointed out. The results of the three different scales techniques (macro, micro and nanoscale) fairly match. The two very different viscoelastic behaviours of PDMS and SU8 resin for the same frequency range have been quantified. Their storage, loss moduli and $\tan (\phi)$ from $0.01 \mathrm{~Hz}$ to some $\mathrm{kHz}$ have been measured. Satisfying global behaviours according to the models and good agreement between measured values and literature ones have been obtained. In conclusion, these three complementary experimental techniques and the developed methods can be used as powerful metrology tools for the mechanical characterization at very small scale of viscoelastic materials. To our knowledge, such a comparison of these three experimental methods applied on viscoelastic materials has not been reported in the literature and highlights the potentialities of these techniques for polymer applications.

Note that as multiple modes were measurable by SMM method (4 modes detected on the SU8 resin), we started to develop a suitable identification procedure to recover both the Young's modulus at different frequencies and the Poisson ratio from SMM measurements.

\section{Acknowledgments}

The authors thank the city of Besançon for supporting this project. The authors acknowledge V. Placet for his assistance for the DMA experiments. 


\section{Figure captions}

Fig. 1: Vibrating sensor of the SMM.

Fig. 2: Principle of the SMM microscope.

Fig. 3 : Model to describe the behaviour of the SMM.

Fig. 4 : Experimental spectra of amplitude of vibration ( $1^{\text {st }}$ mode) as a function of frequency in contact with the two different PDMS samples for a static force of $150 \mu \mathrm{N}$ and for a driving voltage of the bimorph of $1 \mathrm{~V}$.

Fig. 5: Evolution of the measured indentation modulus $E_{m e s}$ as a function of the measured depth penetration $\mathrm{h}_{\text {mes }}$ for PDMS sample $1\left(\mathrm{t}_{\mathrm{v}}=1460\right.$ hours $)$ and different contact stiffness $\mathrm{S}_{0}$. The results are obtained with quasi-static and CSM methods.

Fig. 6: Determination of $\mathrm{E}_{\mathrm{st}}$ (static measurement) and $\mathrm{E}_{\mathrm{dyn}}$ (dynamic measurement) according to Eq. (32) : $\mathrm{E}_{\text {mes }}$ as a function of $1 / \mathrm{h}_{\text {mes }}$.

Fig. 7 : Storage modulus of PDMS samples measured by nanoindentation, DMA and SMM techniques as a function of the working frequency. Simulation with the H-N model.

Fig. 8: Loss modulus of PDMS samples measured by nanoindentation, DMA and SMM techniques as a function of the working frequency. Simulation with the H-N model.

Fig. 9: $\tan (\phi)$ parameter of PDMS samples determined by the three different techniques. Simulation with the H-N model.

Fig. 10 : Evolution of the storage modulus of sample $1\left(\mathrm{E}^{\prime}\left(\mathrm{t}_{\mathrm{v}}\right) / \mathrm{E}^{\prime}(4 \mathrm{~h})\right)$ as a function of the aging time $t_{v}$.

Fig. 11 : Storage modulus of PDMS sample $1\left(\mathrm{t}_{\mathrm{v}}=11000 \mathrm{~h}\right)$ measured by nanoindentation, DMA time-temperature equivalence and SMM techniques as a function of the working frequency. Simulation with the H-N model.

Fig. 12 : Loss modulus of PDMS sample $1\left(\mathrm{t}_{\mathrm{v}}=11000 \mathrm{~h}\right)$ measured by nanoindentation, DMA time-temperature equivalence and SMM techniques as a function of the working frequency. Simulation with the H-N model.

Fig. $13: \tan (\phi)$ parameter of the PDMS sample. Simulation with the H-N model.

Fig. 14: Storage modulus of SU8 resin samples measured with the three techniques as a function of the working frequency. Simulations with the H-N model.

Fig. 15 : Loss modulus of SU8 resin samples measured with the three techniques as a function of the working frequency. Simulations with the H-N model.

Fig. 16: $\tan (\phi)$ parameter of the two SU8 resin samples determined by the three techniques. Simulations with the H-N model. 


\section{References}

1. Rabe U and Arnold W, Appl. Phys. Lett. 64, 1493 (1994)

2. Burnham N A, Kulik A J, Gremaud G, Gallo P J and Ouveley F, J. Vac. Sci. Technol. B 14, 794 (1996)

3. Kolosov O and Yamanaka K, Jpn. J. Appl. Phys. 32, L1095 (1993)

4. Chilla E, Hesjedal T and Frohlich H J Proc. IEEE Ultrasonics Symposium pp. 363-6 (1994)

5. Cretin B and Vairac P Proceedings of the International Seminar on Quantitative Microscopy (PTB-F21 Braunshweig) pp 22-6 (1995)

6. Vairac P and Cretin B, Appl. Phys. A-Mater. supplement to vol. A 66, 235 (1998)

7. Dupas E, Gremaud G, Kulik K and Loubet J L, Rev. Sci. Instrum. 72, 3891 (2001)

8. Oliver W C, Pharr G M, J. Mater. Res. 7, 1563 (1992)

9. Oliver W C, Pharr G.M, J. Mater. Res. 19, 3 (2004)

10. Li X and Bhushan B, Mater. Charact. 48, 11 (2002)

11. White C C, Vanlandingham M R, Drzal P L, Chang N-K and Chang S H, J. Polym. Sci. B 43, $1812(2005)$

12. Sthal F and Cretin B, Appl. Phys. Lett. 62, 829 (1993)

13. Vairac P and Cretin B, Appl. Phys. Lett. 68, 461 (1996)

14. Walberer J A and McHugh A J, J. Rheol : (New York, NY) 45, 187 (2001)

15. Mata A, Fleischman A J and Roy S, Biomed. Microdevices 7, 281 (2005)

16. Roure O, Saez A, Buguin A, Austin R, Chavrier P, Siberzan P and Ladoux B, PNAS 102, $2390(2005)$

17. Schneider F, Fellner T, Wilde J and Wallrabe U, J. Micromech. Microeng. 18, 065008 (2008)

18. Al-Halhouli A T, Kampen I, Krah T and Buttgenbach S, J. Microelectr. Eng. 85, 942 (2008)

19. Cretin B and Vairac P, Appl. Phys. Lett. 71, 2082 (1997)

20. Vairac P and Cretin B, Opt. Commun. 132, 19 (1996)

21. Variac P and Cretin B, Scanning Microdeformation Microscopy : Subsurface Imaging and Measurement of Elastic Constants at Mesoscopic Scale. In Bhushan B and Fuchs H (Eds) Applied Scanning Probe Methods II (Berlin : Springer) pp. 241-281 (2006)

22. Mahaffy R E, Shih C K, Mac Kintosh F C and Ks J, Phys. Rev. Lett. 85, 880 (2000)

23. Le Rouzic J, Vairac P, Cretin B and Delobelle P, Rev. Sci. Instrum. 79, 033707 (2008)

24. Arinéro R, Lévêque G, Girard P and Ferrandis J Y, Rev. Sci. Instrum. 78, 023703 (2007)

25. Haddad Y M, Viscoelasticity of Engineering Materials (London : Chapman and Hall) (1995) 
26. Vairac P and Cretin B, Surf. Inter. Anal. 27, 588 (1999)

27. Tabor D The hardness of metals (Oxford : Clarendon Press) (1951)

28. Loubet J L, Georges J M and Marchesini O, J. Tribol. 106, 43 (1984)

29. Doerner M F and Nix W D, J. Mat. Res. 1, 601 (1986)

30. Briscoe B J, Fiori L and Pelillo E, J. Phys. D Appl. Phys. 31, 2395 (1998)

31. Roche S, Pavan S, Loubet J L, Barbeau P and Magny B, Prog. Org. Coat. 47, 37 (2003)

32. Loubet J L, Oliver W C and Lucas B N, J. Mat. Res. 15, 1195 (2000)

33. Merard K P : Dynamic Mechanical Analysis. A Practical Introduction (CRC Press LLC, USA, 1999)

34. Cunat C, Rev. Therm. 35, 680 (1996)

35. Havriliak S and Negami S, J. Polym. Sci. C 14 ed. R.F. Boyer 99 (1966)

36. Cole K S and Cole R H, J. Chem. Phys. 9, 341 (1941)

37. Davidson D W and Cole R H, J. Chem. Phys. 18, 1417 (1950)

38. Hiver J M 2008, private communication. 
Table 1: Parameters values of equation (38) (39) and (40)

\begin{tabular}{|c|c|c|c|c|c|c|c|}
\hline Specimen & $t_{v}$ & $\alpha$ & $\beta$ & $\tau(\mathrm{s})$ & $\mathrm{E}^{\mathrm{r}}(\mathrm{MPa})$ & $\mathrm{E}^{\mathrm{i}}(\mathrm{MPa})$ & $\mathrm{F}(\mathrm{Hz})$ \\
\hline PDMS (Spec. 1) & $1460 \mathrm{~h}$ & 0.236 & 1 & $210^{-9}$ & 1.65 & 29.6 & $10^{-2}-10^{6}$ \\
\hline PDMS (Spec. 1) & $11000 \mathrm{~h}$ & 0.236 & 1 & $2.10^{-9}$ & 1.9 & 34 & $10^{-2}-10^{6}$ \\
\hline PDMS (Spec. 2) & $>25000 \mathrm{~h}$ & 0.236 & 1 & $2.10^{-9}$ & 2.6 & 44 & $10^{-2}-10^{6}$ \\
\hline SU8 (Spec. 1) & $\begin{array}{l}\sim 1000 \mathrm{~h} \\
\sim 14000 \mathrm{~h}\end{array}$ & 0.4 & 0.38 & 40 & 3600 & 4500 & $10^{-2}-10^{5}$ \\
\hline SU8 (Spec. 2) & $\sim 1000 \mathrm{~h}$ & 0.4 & 1 & 0.5 & 5000 & 5600 & $10-10^{5}$ \\
\hline
\end{tabular}




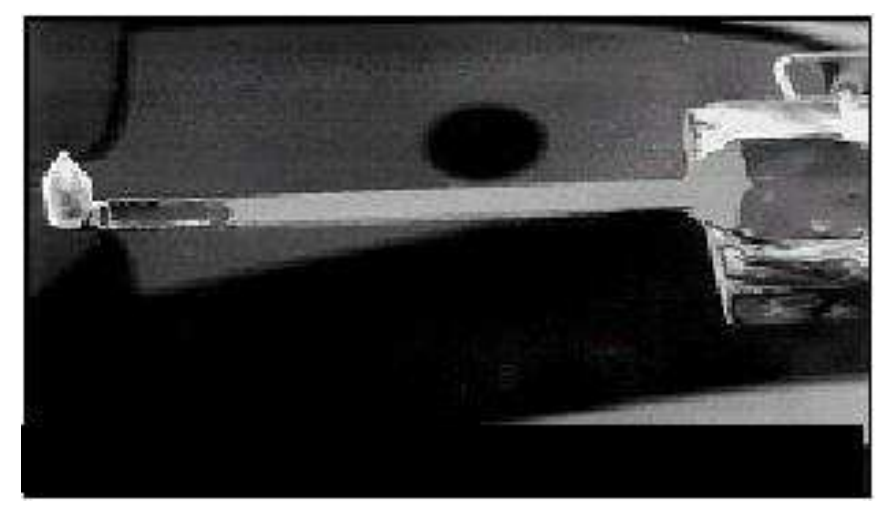

Fig:1

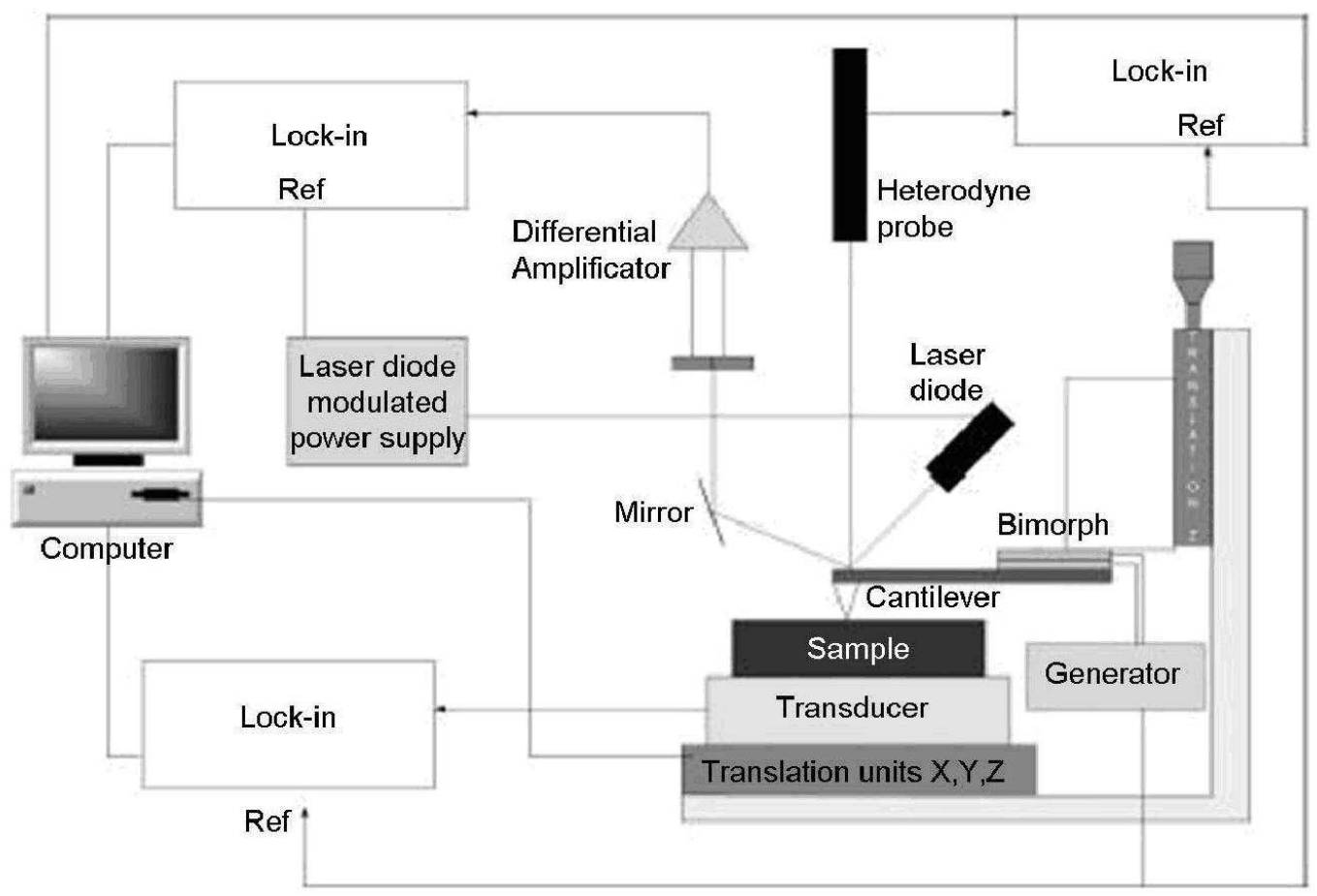

Fig:2 


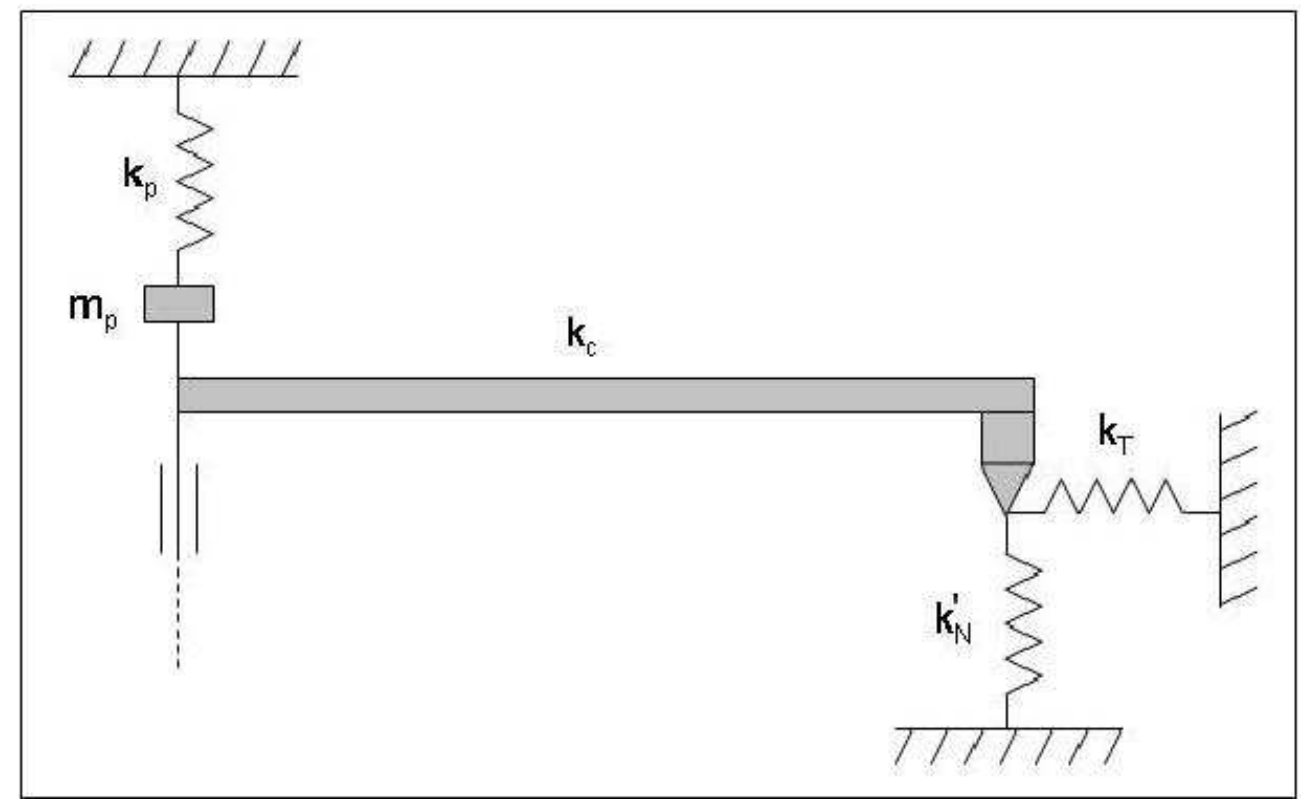

Fig:3

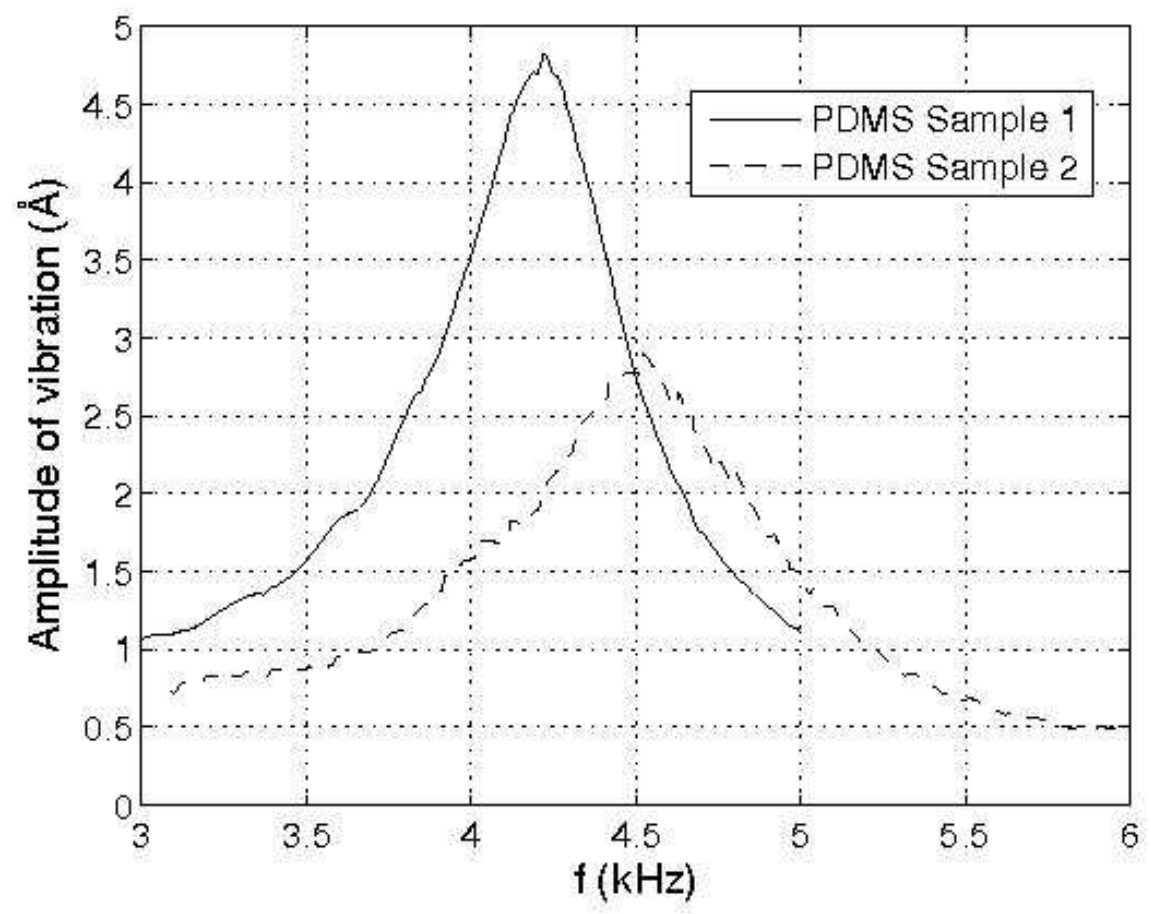

Fig:4 


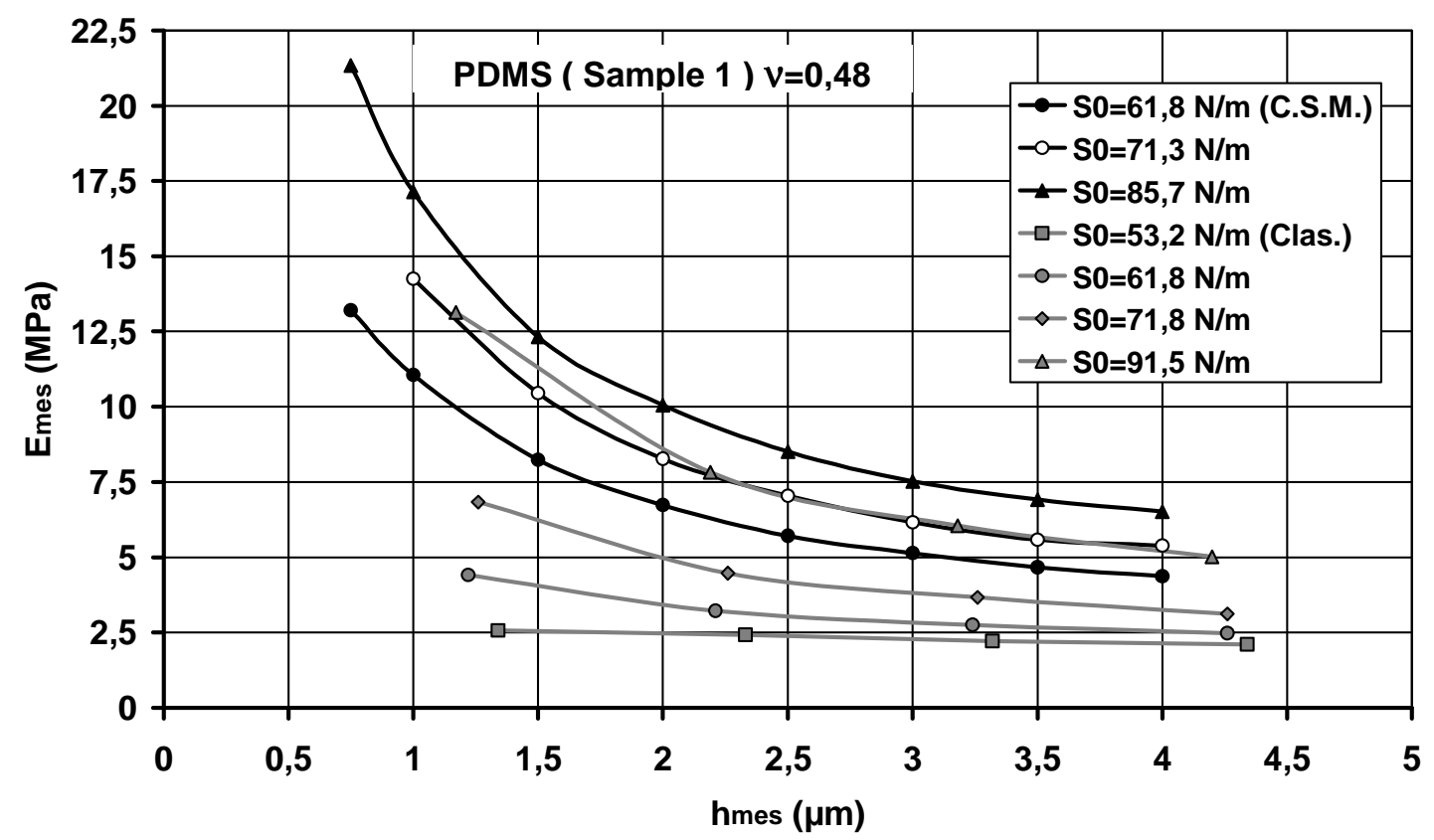

Fig: 5

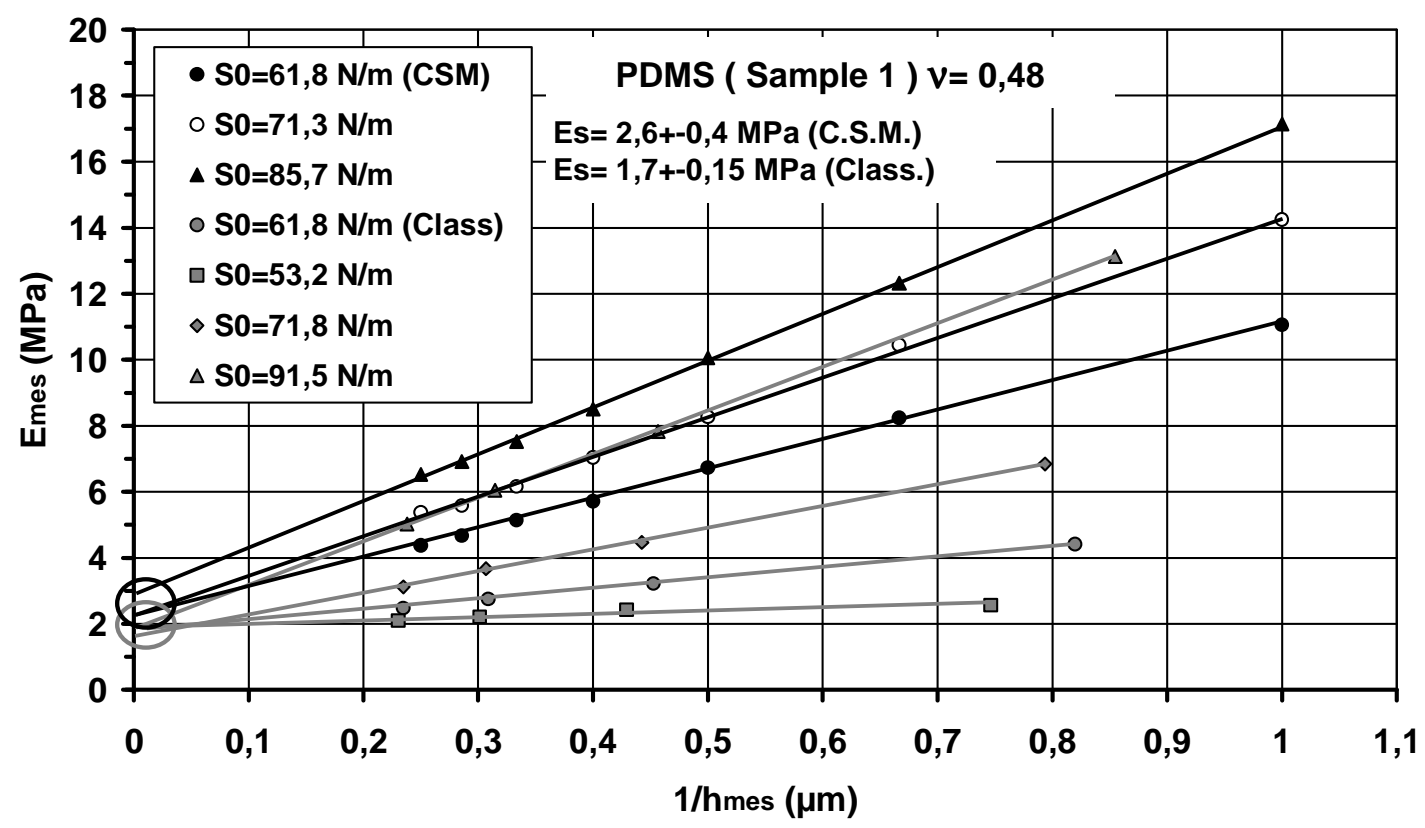

Fig: 6 


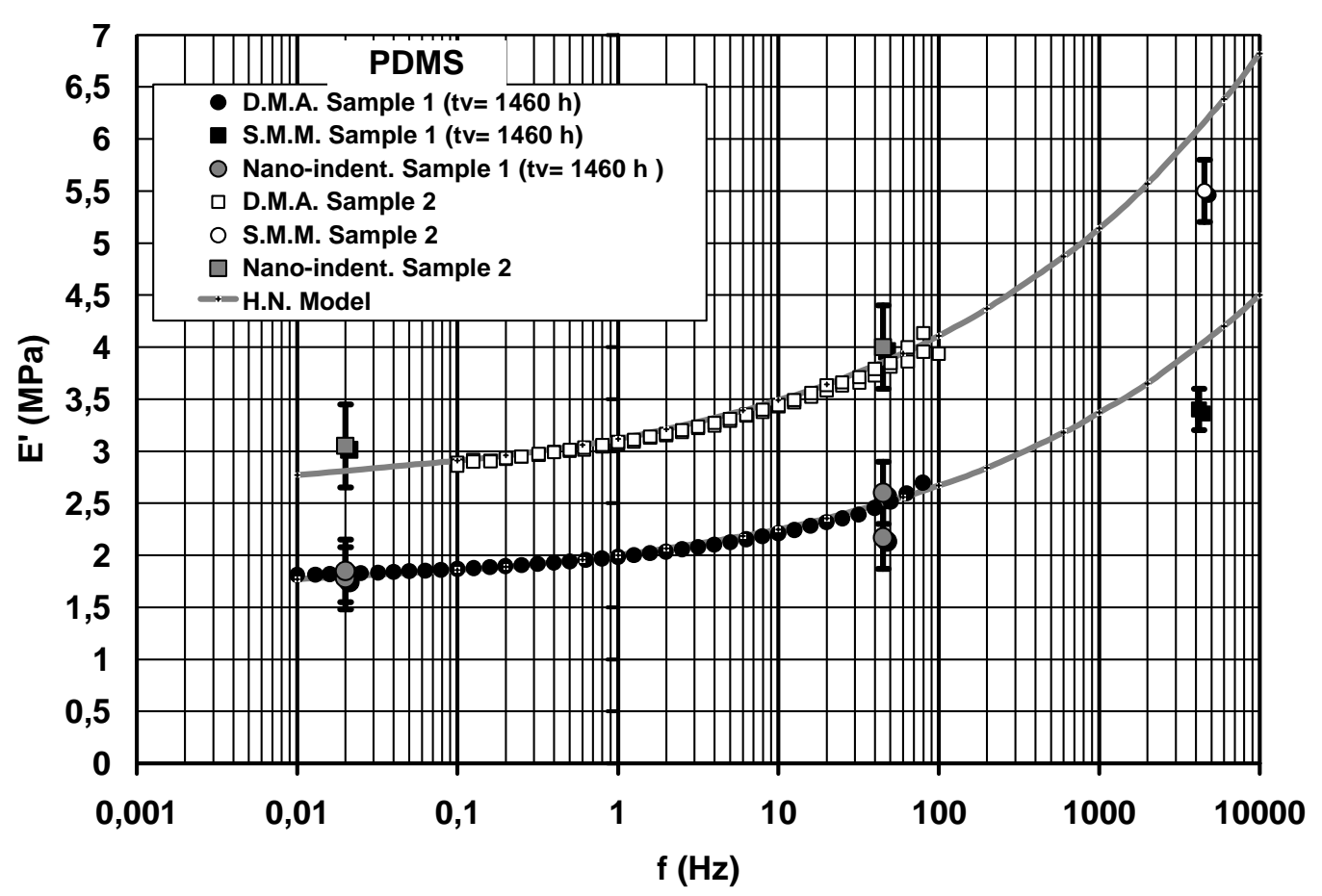

Fig: 7

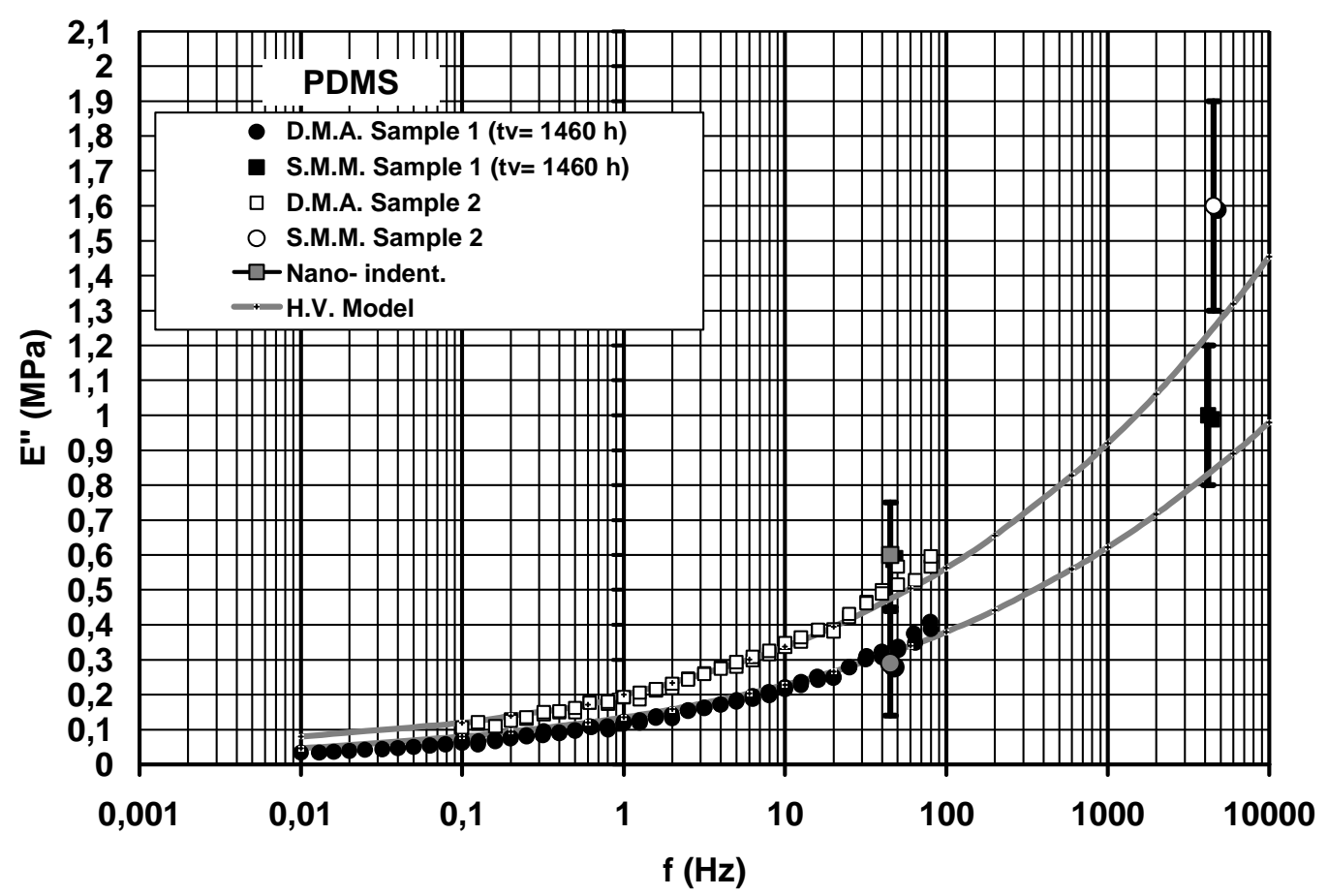

Fig:8 


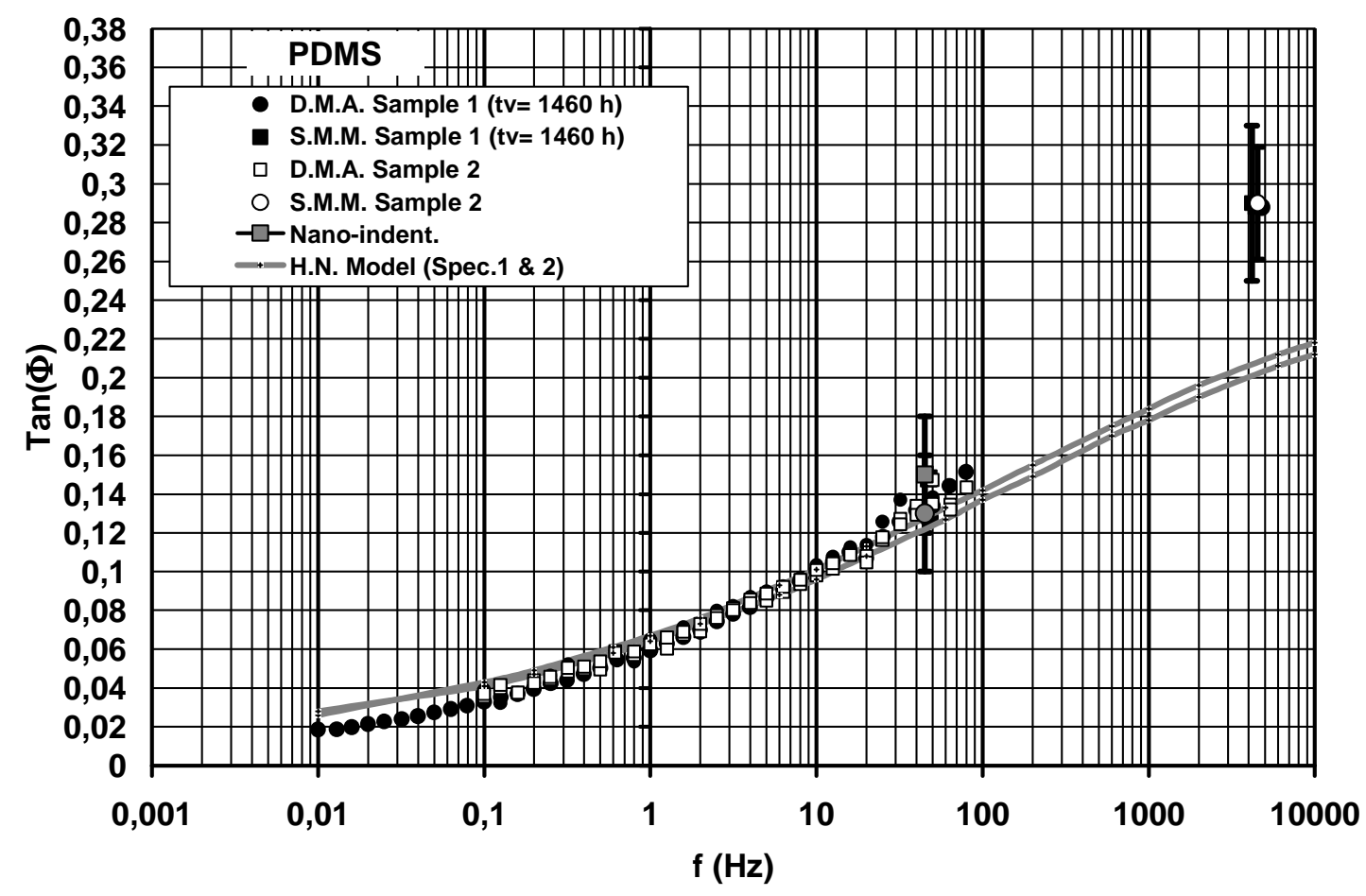

Fig: 9

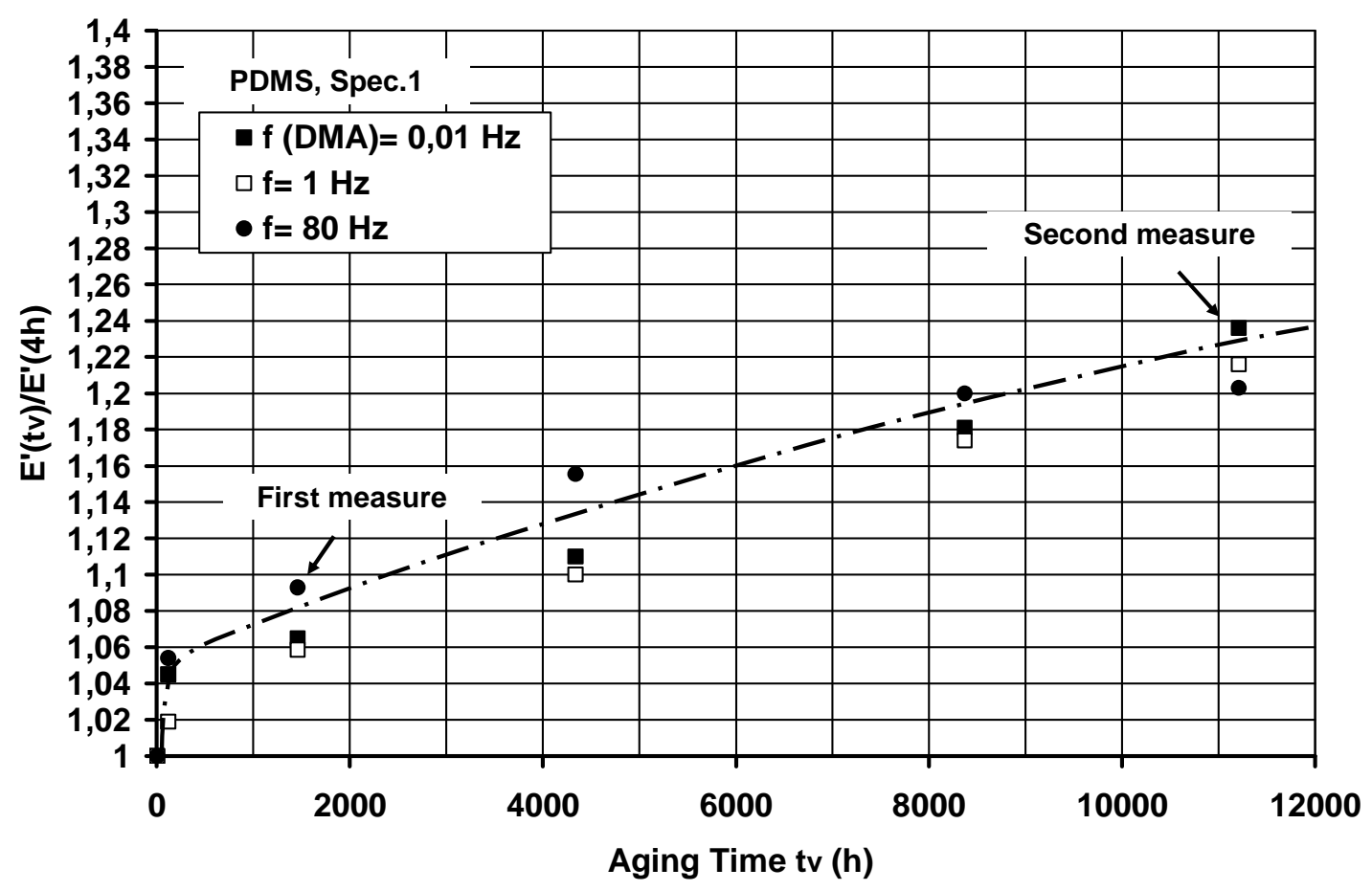

Fig: 10 


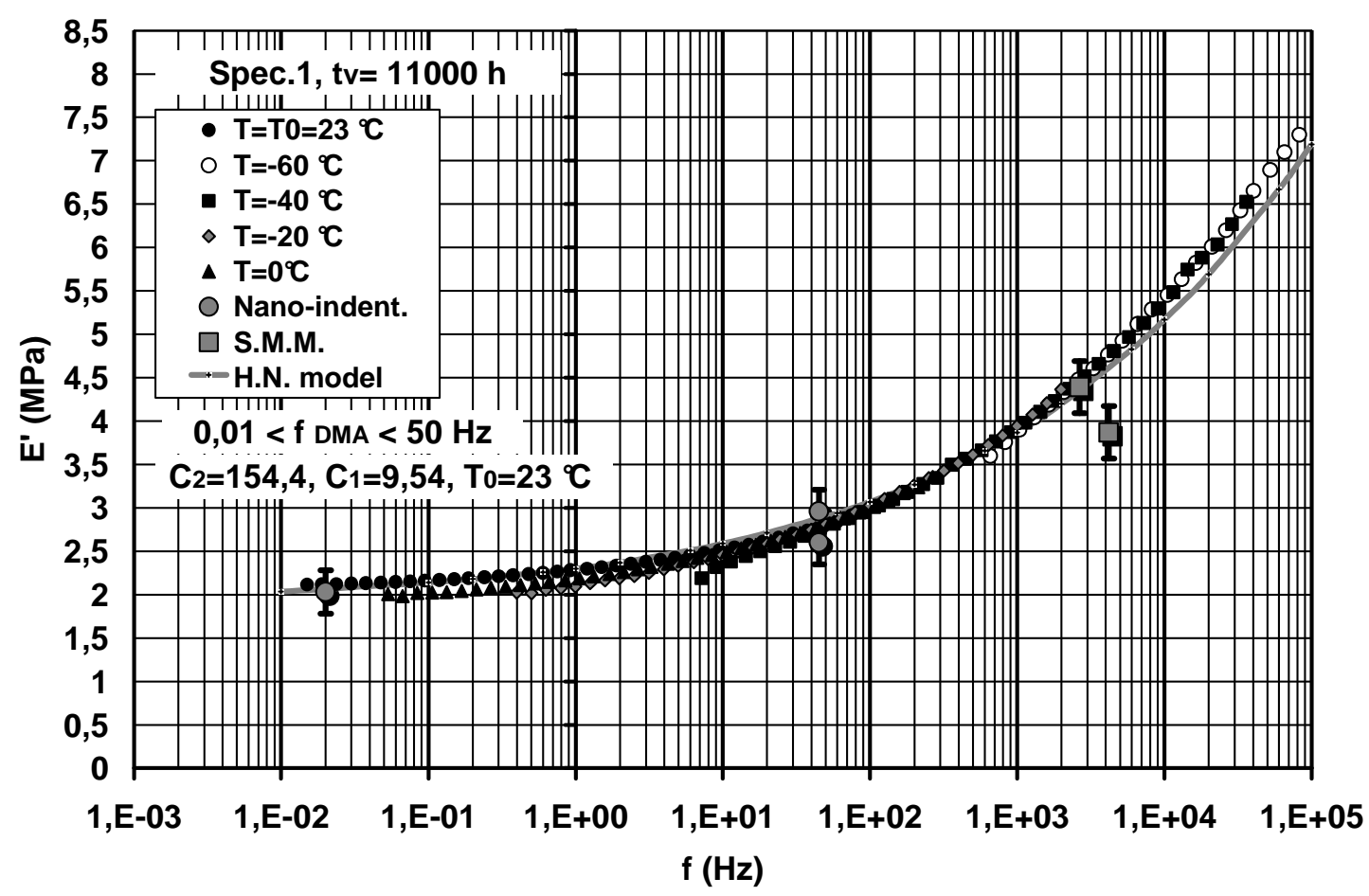

Fig: 11

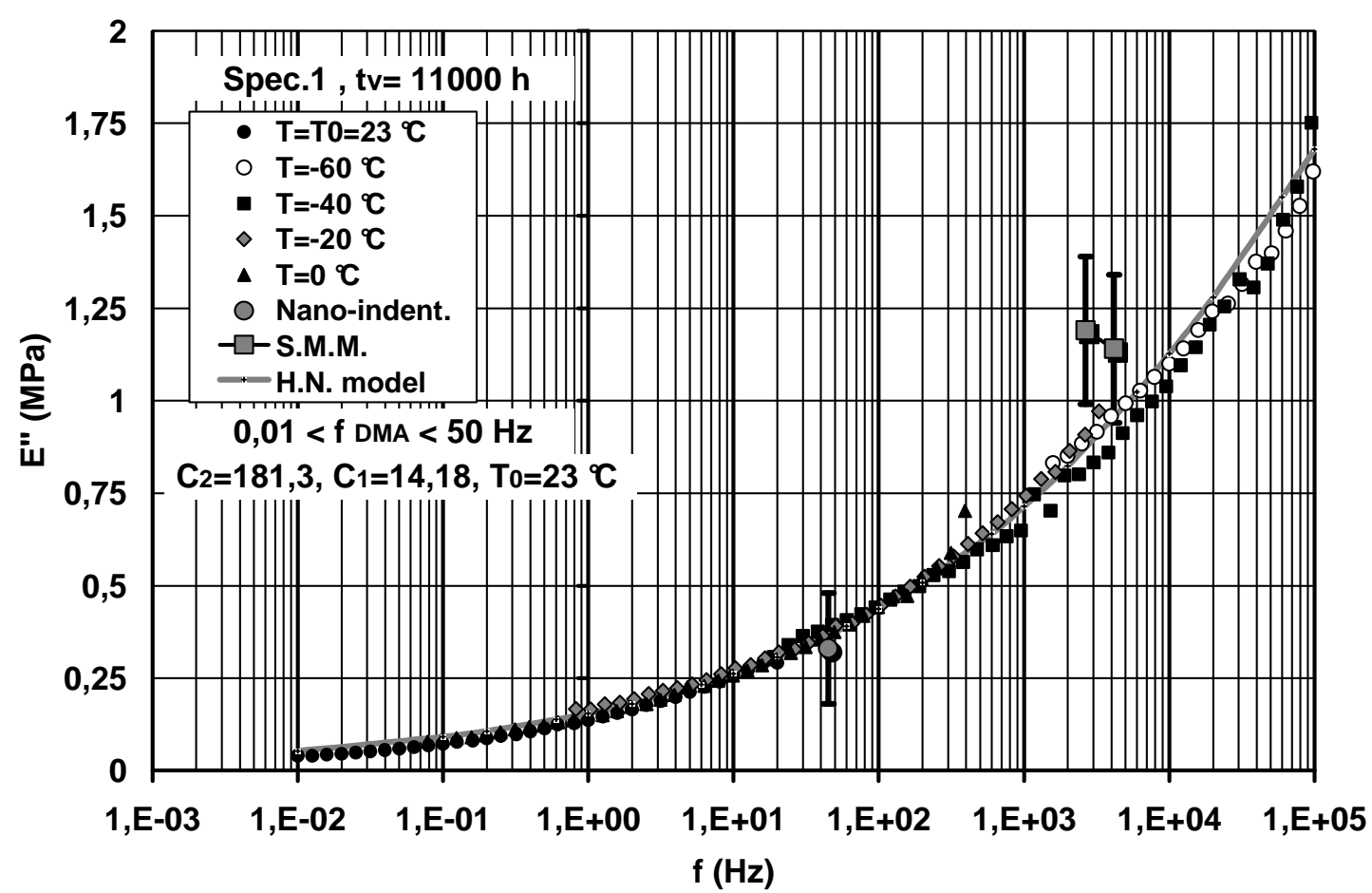

Fig: 12 


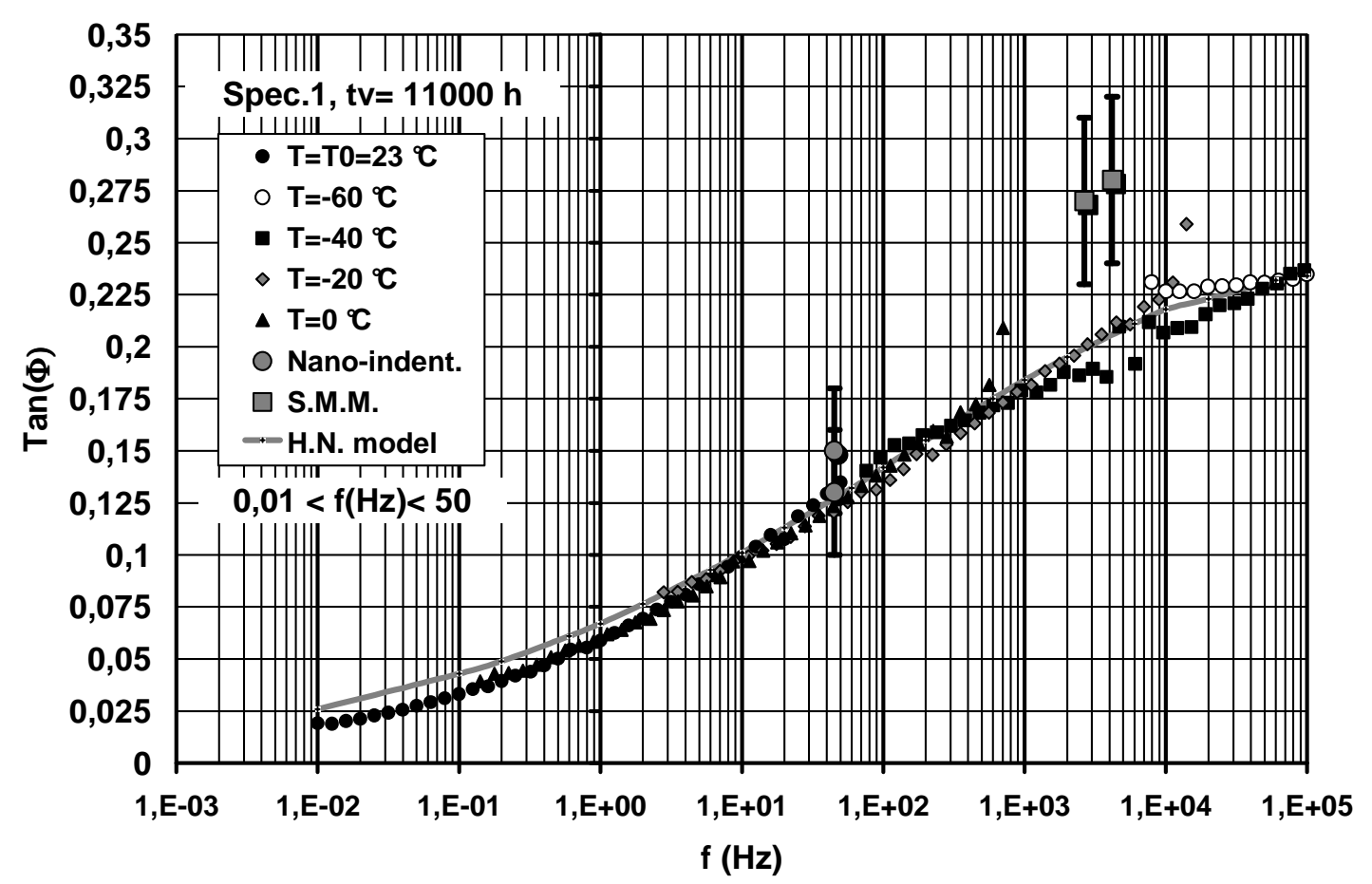

Fig: 13

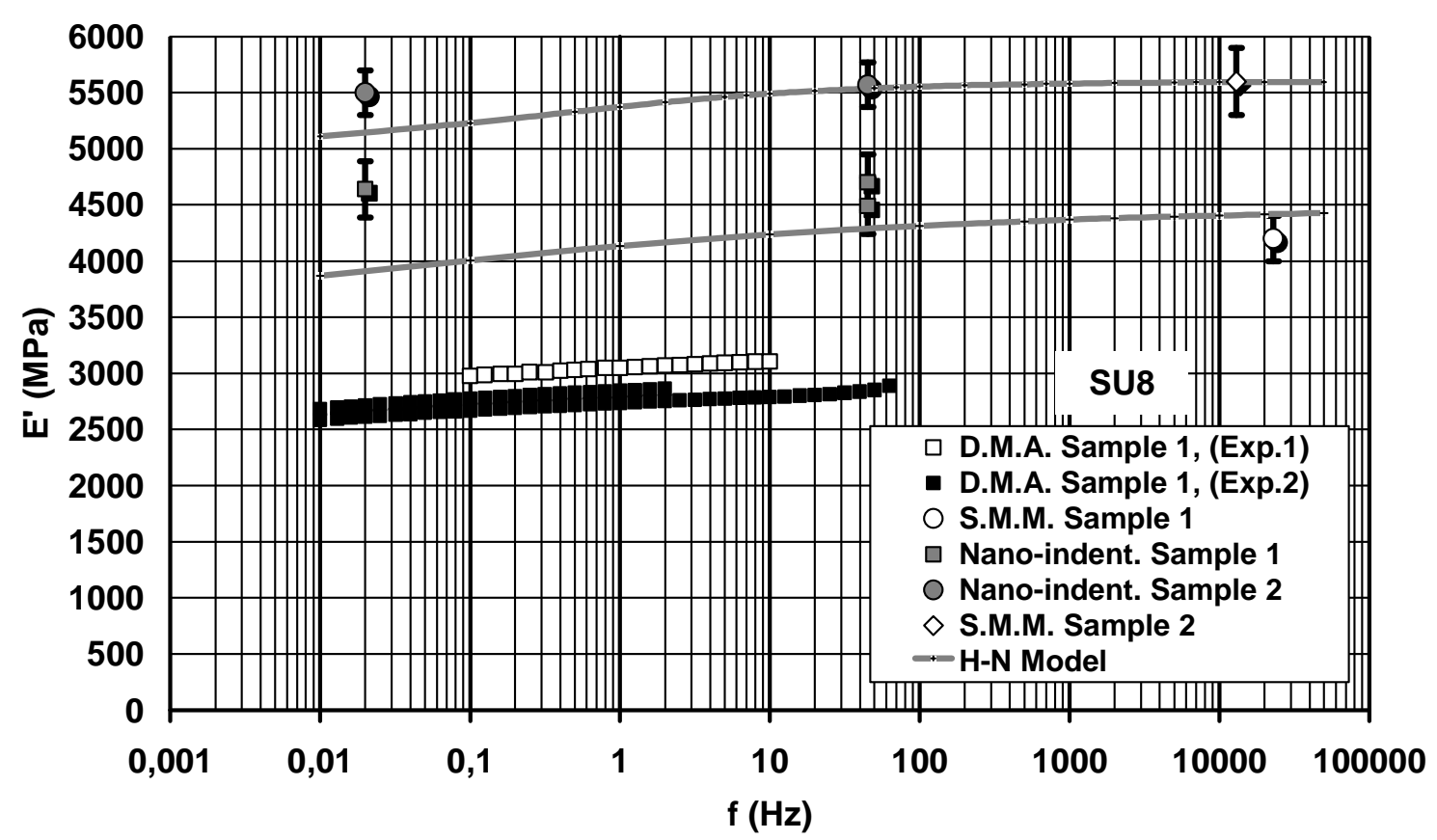

Fig: 14 


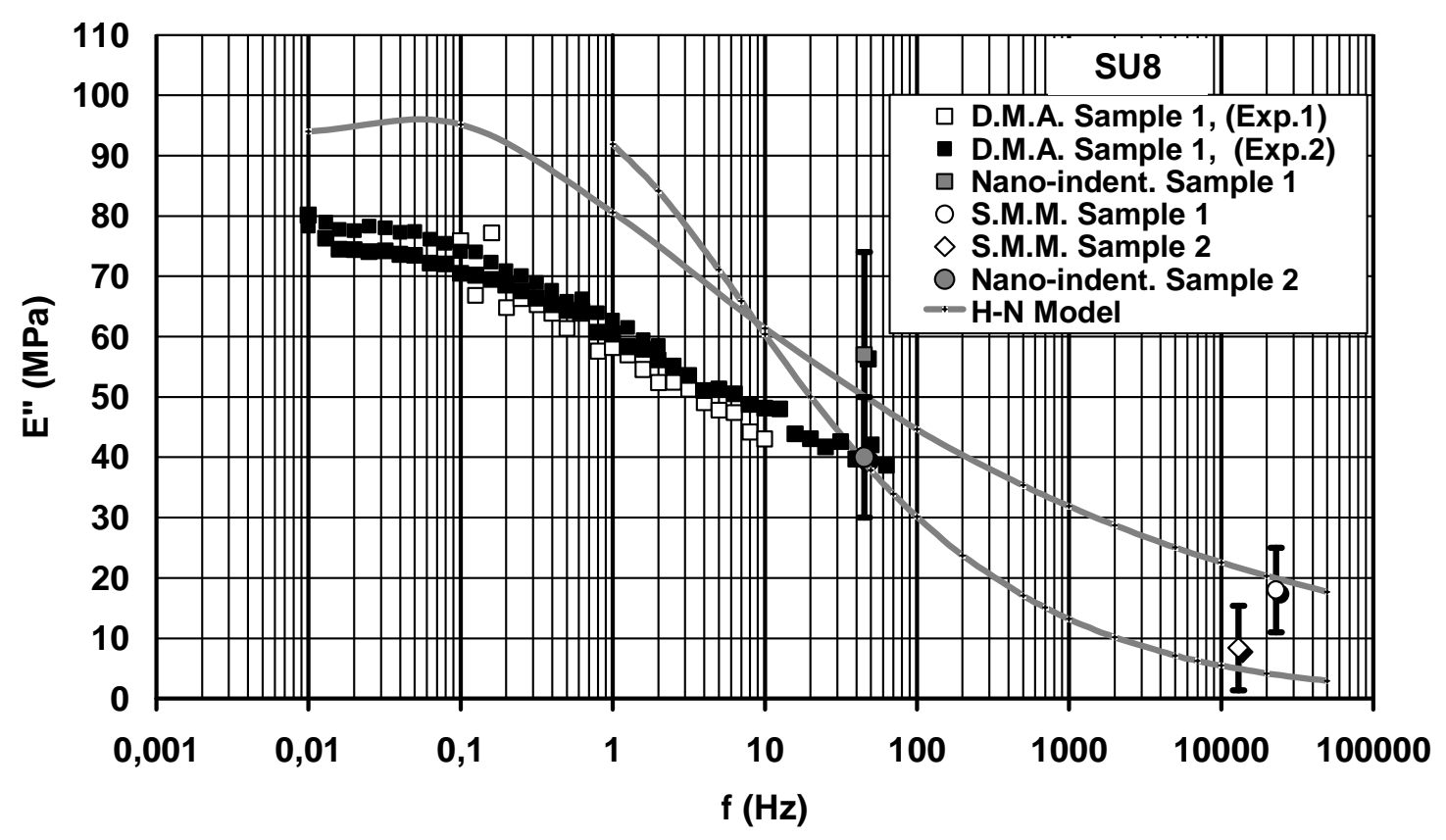

Fig :15

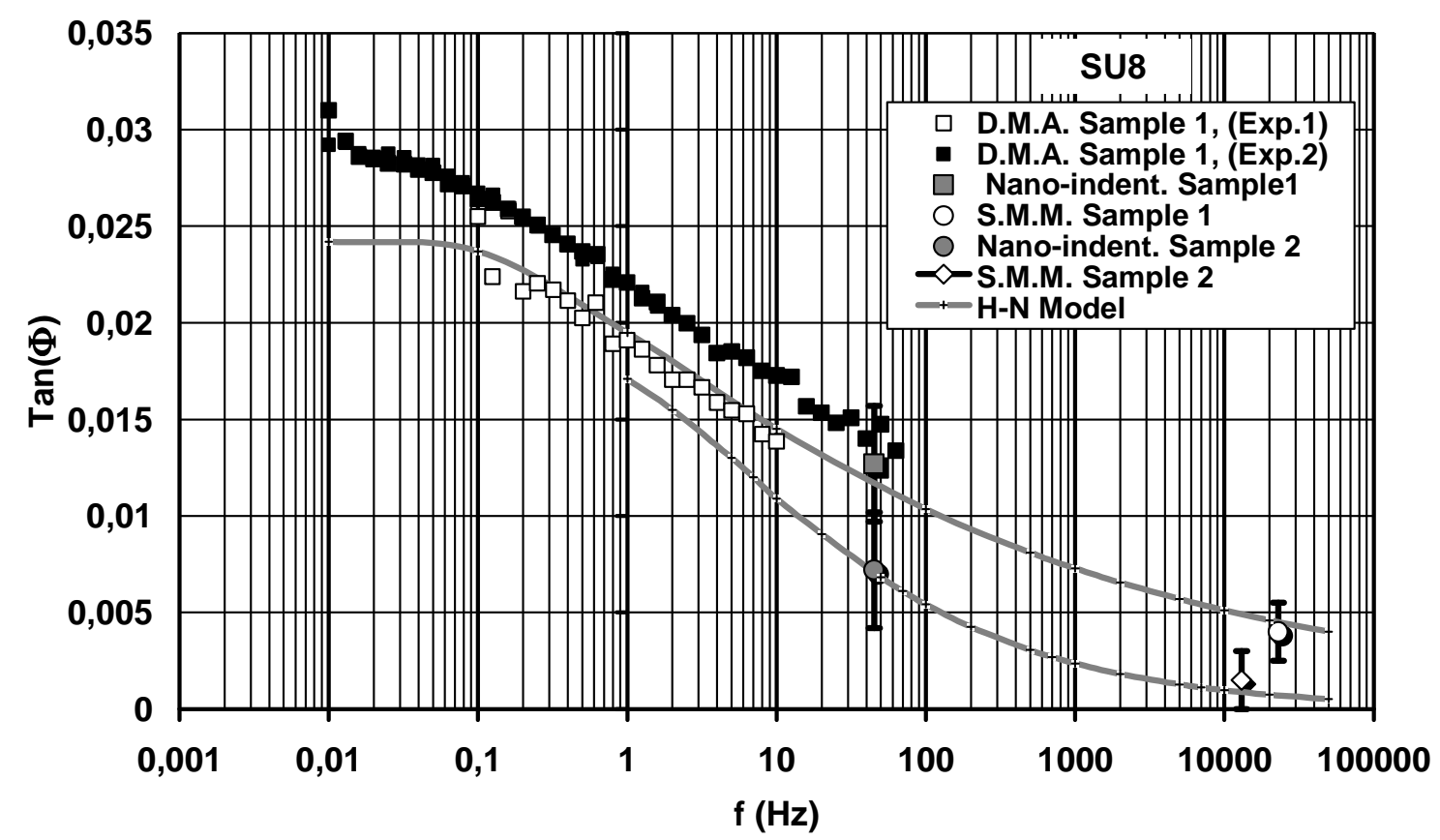

Fig: 16 